\title{
Epistemologías de la Modernidad: entre el etnocentrismo, el racionalismo universalista y las alternativas latinoamericanas
}

\author{
EPISTEMOLOGIES OF MODERNITY: BETWEEN ETHNOCENTRISM, UNIVERSALIST RATIONALISM AND \\ LATIN AMERICAN ALTERNATIVES
}

Dr. Fernando Robles (hrobles@udec.cl) Departamento de Sociología y Antropología, Universidad de Concepción (Concepción, Chile)

\begin{abstract}
In the context of the Eurocentric theories of modernity, the following article addresses four relevant topics and its corresponding deconstruction. 1) Hegel's concept of modernity as the discovery of subjectivity in Western Europe. 2) Max Weber's concept of modernity by emphasizing his criticism of protestant ethic as the engine of capitalism.3) Jürgen Habermas's conception of modernity as 'unfinished project', emphasizing the theoretical structure of the life-world, which occupies a special and important place in his theory of modernity. Finally, I discuss the strengths and weaknesses of the emerging paradigm of decolonization, as a contribution to the improvement of their theoretical positions.
\end{abstract}

Keywords: modernity, eurocentrism, rationality, protestant ethic, world of life, colonialism, modernity.

\section{Resumen}

En el contexto de las teorías de la modernidad eurocéntrica, el artículo siguiente aborda cuatro tópicos relevantes y su correspondiente deconstrucción. En primer lugar, el concepto de modernidad de Hegel como el descubrimiento de la subjetividad europea y occidental. El segundo lugar, el concepto de Max Weber de la modernidad, acentuando la crítica de la ética protestante como motor del capitalismo. En tercer lugar, la concepción de Jürgen Habermas de la modernidad como "proyecto inconcluso", haciendo hincapié en la estructura teórica del mundo de la vida, que ocupa un lugar privilegiado en su teoría de la modernidad. Por último, se discuten las fortalezas y debilidades del paradigma emergente de descolonización, como una contribución al mejoramiento de sus posiciones teóricas.

Palabras clave: modernidad, eurocentrismo, racionalidad, ética protestante, mundo de la vida, colonialismo, modernidad. 


\section{Introducción}

Análogamente a lo que acontece con el concepto de individuo, para una teoría sociológica que se precie de tal, resulta hoy en día indispensable la elaboración y la puesta en uso del concepto de modernidad. Existen múltiples y variadas conceptualizaciones de la modernidad; algunas de ellas acentúan sus aspectos históricos y sus formas de configuración temporal y espacial, otras destacan sus propiedades estructurales y funcionales, mientras que no faltan las que realzan sus propiedades sistémicas y sus riesgos (latentes o construidos).

No obstante, sobre todo considerando la aparición del "proyecto latino/latinoamericano modernidad/colonialidad" (Castro Gómez y Gosfoguel 2007) también conocido como el paradigma emergente de la "escuela de los estudios culturales latinoamericanos" (Lander2000), el tema de la modernidad ha dejado de ser el monopolio temático de pensadores europeos y/o norteamericanos, y la rama de la gestación, de los subterfugios y las consecuencias de la situación actual del mundo moderno comienza a ser pensada y discutida desde los países otrora colonizados.

El pensamiento latinoamericano, acompañado por los estudios de subalteridad provenientes de India y del mundo árabe irrumpe con tal potencia en los contextos académicos, que hasta Habermas, uno de los partidarios más entusiastas de la modernidad europea, calibrada como un "proyecto inconcluso", en un principio equivocadamente identificando al nuevo pensamiento latinoamericano en las cercanías del postmodernismo, se ve obligado a reconocer que "estos enfoques postmodernos denuncian con razón los efectos colonialistas que han resultado en el mundo entero de los patrones y discursos comunicativos de la dominación de proveniencia occidental" (Habermas 1998:221).

Las teorías de la modernidad de talante occidental pretenden alcanzar un grado tal de elaboración, para culminar siendo abstractas y sofisticadas al máximo; sobre todo, de tal manera que mediante un preciosismo extremo, obtengan o que sean capaces de alcanzar una significación tal, que en cada una de ellas ya no sea posible identificar pre-juicos, a prioris, visiones e imaginarios que desenmascaren sus propósitos subyacentes. Por ello son, sin excepción, presuntamente universalistas, es decir, señalan (explícita o implícitamente) que sus pretensiones de validez son omniabarcantes. En cambio, si dejamos de lado la arrogancia universalista y entendemos la historia como una serie de nodos en cuya contextualidad se despliega la heterogeneidad estructural, entonces disponemos del sustento teórico necesario en la perspectiva de las historias, lenguas locales y contextualizadas, en lugar de los grandes relatos. La modernidad es el último de los metarelatos que a Occidente le va quedando.

\section{El armazón primario de la noción de modernidad. Kant, Hegel y la modernidad como la invención de la "subjetividad" occidental ilustrada}

Sabido es que Immanuel Kant, quien por primera vez se refiere explícitamente a la modernidad y la identifica con la Ilustración definiéndola como "la salida del hombre de su minoría de edad. El mismo es culpable de ella. La minoría de edad estriba en la incapacidad de servirse del propio entendimiento, sin la dirección de otro...La mayoría de los hombres, a pesar de que la naturaleza 
los ha librado desde tiempo atrás de conducción ajena, permanecen con gusto bajo ella a lo largo de la vida, debido a la pereza y a la cobardía" (Kant 1965:151).

La decisión de alcanzar la libertad, auto-conduciéndose y prescindiendo de la dirección ajena, es un logro de la razón ilustrada, para la cual sólo puede existir la libertad, lo que conduce paulatinamente a la emancipación del género humano. En otras palabras, sólo por obra de la razón (por definición un estado de reflexión superior a la intuición y al entendimiento) se obtiene la liberación de las ataduras externas, abriendo paso al gobierno autónomo de las acciones. Por consiguiente, sin llustración no es posible la libertad y sin llustración tampoco es viable la modernidad.

Quien perfecciona y estiliza el concepto de modernidad es Hegel: a él se debe recurrir porque es el único filósofo que desarrolla un concepto claro de modernidad. Sólo de este modo es posible comprender a cabalidad cómo la noción de modernidad se trasfiere a la sociología y encuentra sus orígenes en la obra de Simmel y Weber.

La línea divisoria entre la Edad Media y la Edad Moderna tiene una demarcación histórica de orden categórico: el advenimiento de la Reforma y del Renacimiento italiano son sus hitos, que indican el comienzo de una nueva época en la evolución de la humanidad. Hegel es el primero que desacopla a la modernidad de las sugerencias normativas del pasado, hasta que a fines del siglo XVIII, este desembrague se agudiza como producto de la evolución de las ciencias, convirtiéndose en el problema fundamental de la filosofía; dicho con otras palabras, el auto-cercioramiento de la modernidad llevará a los vestigios de la antigua sociedad, a una situación insostenible. Hegel descubre que la subjetividad es el principio rector de la época moderna.

Es a partir de este principio que explicará la superioridad del mundo moderno respecto del pasado y del presente descubierto y colonizado, así como su tendencia hacia la crisis. La subjetividad es una relación exclusiva del sujeto consigo mismo, caracterizada como la tendencia ineluctable hacia la libertad, que se consigue por obra del ejercicio de la reflexión. A juicio de Habermas (1985:29), la subjetividad permite indicar cuatro aspectos distintivos:

a) individualismo: como la capacidad de hacer valer pretensiones individuales

b) derecho a crítica: el mundo moderno exige que aquello que se reconozca, se justifique

c) autonomía de acción: al mundo moderno pertenece que reconozcamos la autoría de nuestros actos

d) filosofía idealista: lo que equivale a que en la Edad Moderna, la filosofía se sabe reconocer a sí misma, por medio de la reflexión

Los acontecimientos necesarios para la institución del principio de la subjetividad, son la Reforma de Lutero, el movimiento llustrado y la Revolución Francesa. Con el auge del Protestantismo, se instituye la dominación de un sujeto que se atiene a sus propias opciones de selectividad. Por otra parte, la Declaración de los Derechos del Hombre como parte integrante del Código Napoleónico, incluye el principio de libertad como constitutiva de la estructura del Estado.

Además, el principio de la subjetividad, condición a las manifestaciones de la cultura moderna, cuestión que se manifiesta en la hegemonía de la ciencia objetiva, que libera al sujeto cognoscente 
produciendo un efecto emancipador en el ser humano. Por otra parte, los conceptos morales de la Edad Media, se redefinen en torno a la medida de la libertad subjetiva de los sujetos. El arte moderno se reordena en torno al principio de la autorreflexión expresiva. En síntesis, en la modernidad el Estado, la religión, la ciencia, la moral y el arte se transforman en expresiones del principio de la subjetividad: "se trata de la estructura de autorelación de un sujeto cognoscente que se vuelve sobre sí mismo como objeto para aprehenderse a sí mismo como en la imagen de un espejo" (Habermas 1985:31).

Es indudable que la subjetividad en el pensamiento hegeliano posee características omnipotentes, al tiempo que se desenmascara como unilateral. Al estar dotada de las propiedades suficientes para producir libertad subjetiva en el sujeto y de erosionar los principios religiosos, se modifica substancialmente el principio unificador de la sociedad, quedando radicado únicamente el sujeto, núcleo gravitante de la totalidad de la filosofía hegeliana. Si la verdadera forma de la realidad exige como su fundamento a la libertad, ésta, la libertad, requiere de auto-conciencia y del conocimiento de la verdad. A su vez, la auto-conciencia y el conocimiento de la verdad constituyen la esencia del sujeto. Luego, la verdadera forma que asume la realidad debe ser concebida como sujeto.

Como, además, todo lo verdadero es real y todo lo real es verdadero, se configura operativamente una tautología perfecta en el ostentosamente llamado "sistema hegeliano". Sin embargo, es menester preguntarse quién es el mentado "sujeto". La respuesta está a la mano en su filosofía de la historia: los "sujetos" son los que están bien encaminados en el logro del espíritu absoluto y "la existencia del espíritu consiste en tenerse a sí mismo por objeto. El espíritu es, pues, pensante; y es el pensamiento de algo que es, y el pensamiento de qué es y de cómo es...El espíritu se hace, pues, una determinada representación de sí, de lo que es esencialmente, de lo que es su naturaleza. Sólo puede tener un contenido espiritual; y lo espiritual es juntamente su contenido, su interés. El saber es su forma y su actitud; pero el contenido es juntamente lo espiritual. Así, el espíritu, según su naturaleza, está en sí mismo; es decir, es libre" (Hegel 1980:62).

Pero si la libertad, surgida de los griegos, fue sólo efímera, parcial y contaminada por la esclavitud "sólo las naciones germánicas han llegado, en el cristianismo, a la conciencia de que un hombre es libre como hombre, de que la libertad del espíritu constituye su propia naturaleza" (Hegel 1980:67). Según Hegel, el mundo se divide en dos: un Viejo Mundo (compuesto por Europa) y un Nuevo Mundo. Así, la conquista de un país del Nuevo Mundo, "se reduce a hacernos saber que se trataba de una cultura natural, que había de perecer tan pronto como el espíritu se acercara a ella. América se ha revelado siempre y sigue revelándose impotente en lo físico como en lo espiritual. Los indígenas, desde el desembarco de los europeos, han ido pereciendo al soplo de la actividad europea. En los animales mismos se advierte igual inferioridad que en los hombres...Estos pueblos de débil cultura perecen cuando entran en contacto con pueblos de cultura superior y más intensa. En los Estados Unidos de Norteamérica, todos los ciudadanos son emigrantes europeos, con quienes los antiguos habitantes del país no pueden mezclarse" (Hegel 1980:171).

Además, los indígenas no sienten estimación propia, sino que son sumisos, serviles o humildes frente a los criollos y mucho más frente a los europeos; más aún, su inferioridad de estos individuos, se manifiesta incluso en su estatura. Ahora estamos en condiciones de constatar que en el "sistema hegeliano", no todos están en condiciones de constituirse en "sujetos". Por 
supuesto que las "culturas inferiores" compuestas por seres humanos de baja estatura (¿como los conquistadores españoles?), sin la más mínima idea de llustración, muy distantes del "espíritu absoluto", no engendran "sujetos" sino -en el lenguaje racista de Hegel- seres inferiores, serviles y minusválidos, incapaces de advertir siquiera la existencia del "principio de la subjetividad", de la cual definitivamente están excluidos.

Si Hegel fue tan ignorante hasta el punto de argumentar que "la fauna (del Nuevo Mundo) tiene leones, tigres, cocodrilos, etc.; pero estas fieras, aunque poseen parecido notable con las formas del viejo mundo son, sin embargo, en todos los sentidos más pequeñas, más débiles, más impotentes" (Hegel 1980:171) y sus argumentos son tan declaradamente racistas, hasta el punto de definir como "el soplo del espíritu europeo" al proceso de exterminio y aniquilación de la que fueron objeto las altas culturas americanas, como la maya, la incaica y la azteca, más preocupante aún resulta una cuestión mucho más actual. Me refiero al silencio cómplice que guardan (hasta hoy) hegelianos reconocidos integrantes de la "teoría crítica" como Horkheimer, Adorno, Marcuse y Habermas frente a las aberraciones racistas de su maestro. Peor aún, si gran parte de ellos (a excepción de Habermas) fueron judíos y huyendo del holocausto, se refugiaron en los EEUU, entonces las palabras "aniquilación", "exterminio", no debiera resultarles tan desconocidas. No me es conocida ni siquiera una línea en sus respectivos escritos, donde se critique, aun temerosamente, el racismo de Hegel respecto de la conquista y la colonización hispánica en América Latina.

Menospreciar a Hegel, sin embargo, sería un grave error. Él es sin lugar a dudas, el secularizador más importante y refinado de las prácticas y dominios epistémicos a los que fueron incorporados indios y africanos desde una historia universal inventada desde la perspectiva cristiana de Occidente. Éstas prácticas arrancaban de la visión "teopolítica" que Isidoro de Sevilla elabora a principios del siglo VII. Según esta invención, el mundo se dividía en partes, cada una de las cuales estaba dedicada a los tres hijos de Noé: Asia a Sem, África a Cam y Europa a Jafet (Mignolo 2007:48). Por supuesto que la situación cambia con Gerardus Mercatus y Abraham Ortelius y su Orbis Universalis Terrarum, pero el mapa original de T en O, de Isidoro de Sevilla, está implícito e invisible en el nuevo Terrarum, sólo que agregándole una masa de tierra desconocida: la futura América.

Es interesante destacar que para Mignolo, la idea del "descubrimiento" corresponde a la visión imperial, que Hegel racionaliza en términos de "modernidad" sustentándose en la cosmovisión cristiana del mundo, mientras que la idea de la "invención" de América Latina abre las puertas del saber descolonizador. Esta es, insólitamente, justamente la postura de Heinz von Foerster, uno de los exponentes más importantes del constructivismo físico-matemático, quien sostiene que los descubrimientos, tal como la "verdad", no existen. Sólo se trata de invenciones sostenidas con argumentos mantenidos en el tiempo con el recurso del poder.

\section{Max Weber y la hipóstasis del principio de la racionalidad: el talante del análisis de la modernidad eurocéntrica y el mito de "ética protestante" como motor del capitalismo}

En su conocido Prefacio a los Ensayos sobre Sociología de la Religión, Max Weber (1997:313-328), sintetiza de manera diáfana, como en ninguno de sus escritos, cómo en Europa se gestó un mundo articulado racionalmente (de acuerdo a la "racionalidad con arreglo a fines" -Zweckrationalität) y 
de qué manera éste rasgo distintivo se hace visible en las distintas esferas de la vida societal. El texto, espléndidamente construido de acuerdo al recurso argumentativo "si-pero", establece una diversidad de distinciones relevantes que estarían presentes en los diversos ámbitos de la vida social de sociedades no-europeas, pero que por carecer de las propiedades correspondientes a la "racionalidad con arreglo a fines", no están dotadas de las pretensiones de validez de la racionalidad imperante, que la modernidad atribuye.

La Zweckrationalität es la acción que más sentido tiene en la clasificación de Weber y la de mayor grado de racionalidad: "Por compartimiento racional con relación a fines ha de entenderse aquel que se orienta exclusivamente hacia fines representados (subjetivamente) como adecuados para fines aprehendidos de manera (subjetivamente) unívoca" (Weber 1993:176). La supremacía de la Zweckrationalität es, de modo ideal-típico, el requisito para la construcción de estructuras sociales modernas, por encima de la acción tradicional y emotiva, las que permanecen siendo tangencialmente relevantes, pero no decisivas.

A pesar de que en otras partes del mundo (China, India o Egipto) han existido una suma de conocimientos empíricos, saberes filosóficos y hasta teológicos, sólo en occidente existe ciencia en el sentido racionalmente válido. La astronomía babilónica carece de fundamentación matemática y a la geometría india la falta la prueba racional, que sólo se creó en Grecia. Así también, a las ciencias naturales, les falta la experimentación racional y el laboratorio moderno, que son producto del Renacimiento. Todas las doctrinas asiáticas acerca del Estado necesitan del fundamento aristotélico y de conceptos racionales que le otorguen fundamento. De modo análogo, a la doctrina jurídica elaborada en el Oriente Medio y en la India, les faltan los rigurosos esquemas y formas del Derecho Romano, y sólo en occidente se conoce una figura como el derecho canónico.

1. En el campo del arte musical se observa por doquiera la existencia de diversos tipos de polifonía, en otras partes del mundo se han calculado los intervalos musicales así como el canto en coros. No obstante, la música armónica racional (el contrapunto como la armonía de los acordes), interpretadas desde el Renacimiento, dan lugar a la orquesta con el cuarteto de cuerdas que acompañado de la notación musical, abre paso a las sonatas, sinfonías y óperas. Para ello, el órgano, el piano y el violín, sólo han existido en occidente.

Respecto de los medios de decoración, en Asia ha aparecido el arco con forma de ojiva. Pero el empleo racional de la bóveda gótica, como principio constitutivo de grandes edificios y como en fundamento de un estilo que incluye escultura y pintura, se produjeron en el medioevo europeo. En otras partes del mundo, falta la racionalización clásica del arte en su totalidad, por ejemplo, el empleo de la perspectiva que el Renacimiento desarrolla. También en China y el Islam existieron instituciones de educación similares a las universidades europeas, pero el cultivo racional y especializado de la ciencia, así como la formación de especialistas, son elementos que sólo han existido en occidente.

2. Lo mismo ocurre con el funcionario especializado, piedra angular de la organización del Estado y de la economía occidental. Los funcionarios (Beamte) han existido también en otras partes del mundo, pero no su encuadramiento en toda la vida social europea, el armazón de una organización de funcionarios especializados. El funcionario moderno es un fenómeno, en especial 
el estatal con formación jurídica, exclusivamente occidental. Igual cosa sucede con la organización estamental del Estado, sólo en occidente ha habido parlamentos más o menos representativos del pueblo elegidos periódicamente. El Estado dotado de una constitución política, con un derecho racional y una administración guiada por reglas racionalmente establecidas (las leyes); sólo en el occidente se conoce ésta combinación peculiar.

3. Otro tanto ocurre con el capitalismo. Porque afán de lucro, la búsqueda de beneficios en dinero, eso no tiene nada que ver con el capitalismo. Al revés, el capitalismo puede ser identificado con el sometimiento de estos impulsos irracionales: la empresa capitalista busca el beneficio sustentable y la rentabilidad. Un acto económico capitalista significa el apoyo en la expectativa de beneficio aprovechado las posibilidades de cambio, vale decir, se levanta sobre las posibilidades de lucro pacífico, mientras que el lucro violento, no es conveniente enmarcarlo bajo la misma categoría de acción orientada hacia las posibilidades de beneficio en el intercambio. A pesar de que tanto la empresa como el empresario capitalista son de larga data y de difusión universal, es en occidente donde el capitalismo ha tenido una relevancia única, que explica la emergencia de formas específicas. Empero, a diferencia del empresario colonial o del explotador de plantaciones con esclavos, o del emprendedor dedicado a la aventura y a la especulación irracional o que se orientaba al lucro por obra de la violencia, occidente conoce en la época moderna otra forma de capitalismo diferente y no desarrollado en ningún lugar de la tierra: se trata de la organización racional-capitalista del trabajo formalmente libre: "La organización racional de la empresa orientada a las oportunidades del mercado, no a la especulación irracional o a la fortuna de la violencia política, no es sin embargo el único fenómeno específico del capitalismo occidental. La organización racional moderna de la empresa capitalista no habría sido posible sin otros dos importantes elementos de su desarrollo: la separación de casa y empresa, algo que domina por completo la vida económica y estrechamente asociada a esa separación, la contabilidad racional" (Weber 1997:321).

Todas estas particularidades del capitalismo occidental operan sólo por su vínculo con la organización del trabajo, sometido al capital. Pero además, como aparte de occidente, el mundo no ha conocido la organización y el cálculo del trabajo, tampoco ha conocido un socialismo racional. Desde hace mucho tiempo ha habido "lucha de clases" en diversas constelaciones, entre estratos acreedores o deudores, entre terratenientes y siervos, o entre arrendatarios y terratenientes, pero falta la contradicción moderna entre el gran empresario industrial y el trabajador asalariado libre. Para el desarrollo del capitalismo, se necesita del desencantamiento de las cosmovisiones metafísico-religiosas y de la constitución de estructuras de conciencia funcionales a la modernidad. Weber concibe, análogamente a Marx, la modernización de la sociedad como diferenciación de la economía capitalista y del Estado moderno. Ambos complementan sus funciones y se estabilizan mutuamente. El núcleo organizacional gravitante lo configura la empresa capitalista.

4. Visto desde la historia de la cultura, se trata de la aparición de la burguesía occidental y sus singularidades, aparejadas al advenimiento de la organización del trabajo capitalista. De tal manera que "el burgués" es propio del occidente. La racionalidad del capitalismo occidental está condicionada por el carácter calculable de los factores técnicamente decisivos. Es decir, la singularidad de la ciencia occidental (ciencias naturales) expresada en el uso de las matemáticas y la experimentación, son el pivote de apoyo técnico que hace posible el capitalismo occidental. Por 
su parte, la ciencia y la técnica reciben el apoyo y el impulso decisivo de la empresa interesada en sus resultados. Los indios también calculaban y practicaron el álgebra, pero todo aquello no produjo en la India ni cálculo moderno ni balances; sólo en occidente la ciencia se puso al servicio del capitalismo emergente. Si bien la aparición de las matemáticas y de la mecánica no surgió desde los intereses capitalistas, el empleo de conocimientos científicos fue decisivo para la regulación de la vida de las masas.

5. De allí que la estructuración racional del derecho y la administración, concomitantes con la configuración de la actividad económica, garantizaran la posibilidad de un cálculo seguro. Sólo occidente disponía de este derecho y esa administración con ese formalismo y esa perfección técnico-jurídica. Los privilegios obtenidos por el estamento jurídico especializados en derecho racional, no son una mera casualidad. Pero no fueron ellos quienes crearon ese derecho, sino que otros poderes racionalizantes.

En la visión somera de los casos mencionados, se trata del "racionalismo" del cual está dotada la cultura occidental. Así como existen "racionalizaciones" de la conciencia mística, en todas las culturas han existido "racionalizaciones" en los más variados ámbitos de la vida. Pero lo que marca la diferencia es, ante todo, las esferas y la dirección de la racionalización. La singularidad del racionalismo occidental consiste en que las esferas que abarca contribuyen y desatan un desencantamiento irreversible del mundo.

Todo intento de explicación debe considerar las condiciones económicas, dada la relevancia fundamental de la economía, sin desatender la relación causal inversa, pues el desarrollo económico depende de la disposición de los hombres a determinadas formas de vida prácticoracionales. Allí donde esta regla de conducta se bloquea por obra de obstáculos de orden espiritual, también el desarrollo de la vida económica de carácter racional se encuentra con fuertes resistencias internas. De allí la importancia de dilucidar cómo determinadas creencias religiosas, condicionan la aparición de un Ethos económico específico, el talante económico moderno, funcional con la ética racional protestante.

Al renunciar al mundo, el ascetismo que en un principio huía del mundo, refugiándose en la soledad, logra dominar el mundo desde los monasterios y claustros durante el medioevo. Ahora, en los intersticios de la modernidad, se va a producir el fenómeno contrario: se lanza al mercado de la vida, cierra las puestas de los claustros y se dedica a impregnar con su método de vida a la que transforma en racional, pero no de este mundo, sino que para este mundo. Pero el desencantamiento del mundo y la eliminación de la magia como medio de salvación no fueron realizadas en la piedad católica con la misma consecuencia que en la religiosidad puritana: "Para el católico, la gracia sacramental de su Iglesia estaba a disposición como medio de compensar su propia insuficiencia: el sacerdote era el mago que realizaba el milagro del cambio y tenía en sus manos el poder de las llaves; se podía acudir a él con arrepentimiento, y él administraba las penitencias u otorgaba esperanzas de gracia, seguridad de perdón y garantizaba la emancipación de la terrible angustia" (Weber 1969:184).

Todo ello se modifica substancialmente con la Reforma de Lutero: éste, al convertir a la Iglesia en cuasi efímera, estableciendo una posibilidad de conexión directa hombre-Dios, rompe con las ataduras institucionales del dogma eclesiástico, estableciendo una dinámica coherencia entre la 
responsabilidad individual y la capacidad de decisión en los seres humanos, los que deben responder únicamente por sus actos ante Dios, suprimida la autoridad de la burocracia eclesiástica. Por tanto, lo específico de la Reforma, en contraste con la concepción católica, es haber acentuado al matiz ético, manifestado en la posibilidad de trabajo en el mundo, es decir, racionalizando la praxis de la profesión.

La evolución del concepto guarda obviamente una íntima relación con las distintas formas de piedad de cada una de las Iglesias reformadas. Mientras que en especial la doctrina de Pablo, adopta una actitud indiferente y tradicionalista ante la vida profesional, a la espera del Señor, e invita a seguir trabajando en el mundo en lo que haya encontrado, la situación cambia substancialmente con la Reforma: "lo absolutamente nuevo era considerar que el más noble contenido de su propia conducta moral consistía justamente en sentir como un deber el cumplimiento de la tarea profesional en el mundo" (Weber 1969:89). Con ello, se genera un concepto ético-religioso de la profesión que cada uno ejerce, concepto que traduce el dogma común a todas las confesiones protestantes, en oposición a la ética de catolicismo.

Conocida es la enigmática postura de Weber frente al imperativo de racionalización, entendida como primacía de la Zweckrationalität, que se articula y manifiesta como inevitable y que abarca todas las esferas de la vida: economía, ciencia y tecnología, arte, política, educación, intimidad, derecho, moral, erotismo, etc. (Habermas 1981:326). Jamás escondió, como en el texto que al principio comentamos, su admiración por los diversos complejos de racionalidad surgidos en occidente y tampoco dejó de manifestar su descontento porque la sociedad se convertiría, más temprano que tarde, en una "jaula de hierro" de la cual no podríamos salir.

Tres son las impugnaciones que a Weber se le pueden imputar, la primera se remite obviamente a su concepto de racionalidad moderna, occidental y europea; la segunda se refiere a la autenticidad histórica con la que argumenta la exclusividad "occidental" de la modernidad como proyecto de sociedad; la tercera pone en tela de juicio el rol de la ética protestante en la gestación del Ethos de convicción capitalista.

1.- ¿Es posible sostener que existe una única forma de "racionalidad", la que proviene del pensamiento europeo? ¿Qué se entiende por racionalidad europea? La racionalidad, se sostiene, es la capacidad que permite pensar, evaluar y actuar de acuerdo a ciertos principios de optimización y consistencia para satisfacer algún objetivo o finalidad. Mediante el uso de la razón, el ser humano, el único portador de sentido según Weber, intenta elegir para conseguir los mayores beneficios, de forma económica, política, social o individual, desde las variadas limitaciones del entorno (externo) y del cerebro (entorno interno). Cualquier construcción mental llevada a cabo mediante procedimientos racionales, tiene por tanto una estructura lógicomecánica distinguible, mediante el uso del razonamiento. Esto es también valido, si las tipologías de racionalidad de ordenan como se desee (con arreglo a fines o con arreglo a valores).

La racionalidad europea nace con Descartes, quien sustituye el antiguo dualismo "cuerpo"/"nocuerpo" (propio del pensamiento medieval), por uno de nuevo cuño, en que se opera una separación radical entre "razón-sujeto" y "cuerpo". La razón ya no es la secularización del alma sino que una "res cogitans" (razón-sujeto), respecto de la cual el cuerpo no puede ser sino un residuo de animalidad o un simple objeto del conocimiento (Descartes 1974:113). La primacía de 
la razón (proyectada en el alma), el desprecio por la mortalidad y el ineluctable envejecimiento del cuerpo, es uno de los lastres más estables del pensamiento europeo, del cual ha tratado de librarse con más o menos éxito. Uno de los más serios intentos de emancipación es el que emprende, desde la fenomenología de la percepción, Maurice Merleau-Ponty, y otro más reciente y mucho más contestatario, es el del filósofo alemán Peter Sloterdijk. La despedida del cartesianismo que Husserl emprende, se autobloquea debido al carácter trascendental que adopta el método de la(s) reducción(es) fenomenológicas (epojé). Desde la epistemología, es considerable el esfuerzo de Paul Feyerabend y su teoría de la inconmensurabilidad y uno de los esfuerzos más notables, desde una fenomenología mundana, es el de Alfred Schütz.

En cualquier caso todas las estrategias de liberación del racionalismo se efectúan desde el interior de la episteme de la modernidad; incluso las más variadas tendencias del pensamiento postmoderno, operan sin transgredir sus demarcaciones. De entre ellas, merece mencionarse la elaborada por Luhmann desde el constructivismo operativo. Luego de hacer añicos al racionalismo, entre otras cosas porque se niega a observar sus propias paradojas, abandonando y/o rechazando la observación de observadores, pues dicha estrategia significa negar la racionalidad del mundo (configurado por distinciones construidas), señala lo siguiente: "Los europeos estamos acostumbrados a transformar culturas ajenas de lo incomprensible a lo comprensible. La comunicación mundial les ha obligado a ello, especialmente desde el descubrimiento de América, que coincidió con la invención de la imprenta. Tienen especialistas para hacerlo: etnólogos, orientalistas, científicos de las religiones, psicoanalistas. Y también estamos acostumbrados a críticas de la ideología, a ver que los otros no ven lo que no ven. Pero la racionalidad, si se quiere retener la vieja referencia mundial del concepto y no seguir las modernas desviaciones, sólo se podrá recobrar si se redondean aquellas costumbres con una conclusión autológica. Si se aplica a aquél que la practica y se convierte así en universal. Entonces se trataría de entender que no se entiende lo que no se entiende, y probar semánticas que se las arreglen con ello" (Luhmann 1997:85).

Toda operación por autología tiene dos consecuencias inevitables: en cualquier argumento produce nuevas paradojas, las que se convierten en insolubles, obligando a evitar cualquier recurso a la verdad o a la evidencia, y produce tal grado de indeterminabilidad haciendo imposible cualquier distinción sujeto-objeto.

Además, la racionalidad que se observa en el mundo es policéntrica, y no eurocéntrica y de ello da cuenta la emergencia de una nueva episteme, distinta a la de la modernidad. Al romperse la lógica de las esencias, se abre paso a una forma distinta de racionalidad. Esto significa que existe en este mundo de vida una postura precomprensiva externa a la modernidad. En otras palabras: no se puede eludir el tema de las vivencias, porque el pueblo en Latinoamericano vive en un mundo de cosas sino en un mundo-de-personas. En contraposición al estar en la riqueza, el proyecto del mundo popular es estar-en-la-relación. Esto significa que estamos frente a una episteme radicalmente distinta a la moderna. No interesa si esta es descrita como premoderna, rural, medieval o como se quiera. Es distinta, despreciada, marginada, pero puede ser una comprensión del todo-real fecundo.

Desde la misma episteme moderna, Josetxo Beriain, ha propuesto una solución muy interesante: frente a la pretendida unicidad de la modernidad europeo-occidental, Beriain sostiene el derecho 
a existencia de "modernidades múltiples": la modernidad de corte occidental, tal como la conocemos de Max Weber, sobrecargada de paradojas, incertidumbres, riesgos y cuestionamientos "inequívocamente pone de manifiesto la cara más tenebrosa y despiadada de la 'modernidad', (que) es su incapacidad para erradicar la barbarie, proyecto normativo de los sociólogos modernizadores, dicho de forma más radical, es su 'pacto con el diablo', en su promesa monstruosamente incumplida de libertad..." (Beriain 2005:9). La noción de las modernidades múltiples, implícitamente inspirada en las "realidades múltiples" de Schütz, presupone la idea de entender el mundo contemporáneo viéndolo como una historia de discontinuas constituciones y reconstituciones de una multiplicidad de programas culturales. Si es posible postular la existencia evidente de modernidades múltiples, me pregunto si no es menester también considerar la existencia y las potencialidades de "racionalidades múltiples", contextuales, indexicales (como lo propuso Garfinkel), particularizadas y remitidas a contexturas de acción y comunicación, que entregan una visión similar al bricolage del que habla Levi-Strauss, refiriéndose a la "ciencia de lo concreto" (Levi-Strauss1972:35) o a la importancia de los intersticios de modernidad relacional, puesto de manifiesto en las loterías clandestinas de los barrios caraqueños (Moreno 2000:227).

2. Cuando Weber sostiene que el pensamiento occidental es el heredero de la cultura griega y romana, repite la falsedad histórica que caracteriza al eurocentrismo autosuficiente. Grecia fue siempre mucho más asiática que occidental: Aristóteles, por ejemplo, fue estudiando como lógico y metafísico en Bagdad mucho antes de ser traducido en la España musulmana al latín y llegó a París recién a finales del siglo XII, de tal manera que la cultura griega llega a occidente por la mediación de la intelectualidad musulmana; el uso que de Aristóteles hacen filósofos cristianos como Abelardo y Tomás de Aquino (en contra de la escolástica de Agustinus), se debe a que los musulmanes recuperaron y conservaron su pensamiento. Por otra parte, el Imperio Romano es destruido definitivamente en el año 473, luego de ser invadido por las tribus germánicas, hasta que Odoacro destituye definitivamente al último emperador del Imperio Romano latino (Rómulo Augústulo) y envía las insignias imperiales a Zenón, el emperador romano de Oriente, donde se hablaba griego.

El imperio romano bizantino, de carácter multiétnico, tenía una estructura política y social completamente distinta al occidental, y es absolutamente improbable que en los márgenes de su territorio, el derecho romano haya tenido algún grado de validez práctica. Posteriormente a la caída de su capital, Constantinopla, en 1453, por obra de la superioridad político-militar musulmana y casi concomitantemente con el advenimiento del Renacimiento italiano, se comienza a gestar el mito de la ideología eurocéntica, impulsada con entusiasmo por el romanticismo alemán: "misteriosamente, lo occidental-latino, se une a lo griego oriental y, en confrontación con el imperio musulmán, se genera la siguiente ecuación: Occidental = Heleno + Romano + Cristiano" (Dussel 2000:62). De ésta visión eurocéntrica, provinciana y regional, es víctima el pensamiento weberiano y el molesto exclusivismo europeo de su visión de la modernidad.

El meollo de la cuestión es que debemos oponernos a la opinión hegemónica, en cuanto a la génesis de la modernidad europea. Hay, someramente hablando, dos conceptos de modernidad:

(a) El primero es eurocéntrico, provinciano y regional. La modernidad se concibe como la salida de la inmadurez por un esfuerzo de la razón crítica, que abre a la humanidad (los europeos) una 
nueva fase en el desarrollo del ser humano. Este proceso se daría en Europa, esencialmente en el siglo XVIII. El espacio y el tiempo es descrito por Hegel y comentado por Habermas; esto es unánimemente aceptado por la tradición europea actual. Lo que caracteriza a la modernidad es el descubrimiento de la subjetividad y los acontecimientos claves son tres: la Reforma, la llustración y la Revolución Francesa. Siguiendo la misma secuencia espacio-tiempo se habla además del Renacimiento Italiano, la Reforma, la Ilustración Alemana y la Revolución Francesa. Si le agregamos al parlamento inglés, se puede decir: Italia (siglo XV) $\rightarrow$ Alemania (siglos XVI-XVIII) $\rightarrow$ Francia (siglo XVIII) $\rightarrow$ Inglaterra (Siglo XVII).

Esta se denomina visión eurocéntrica porque indica en el punto de partida de la "Modernidad" fenómenos exclusivamente intra-europeos, por lo que el desarrollo posterior de la "Modernidad" no necesita más que a Europa para explicarlo. Esta es la visión que comprende la sociología convencional, desde Max Weber hasta Habermas. Entonces, resulta relativamente fácil nombrar a Galileo (condenado en 1616), a Descartes y a Bacon como los inspiradores intelectuales de este proceso.

(b) Dussel (2000:59) propone una segunda visión de la "Modernidad", que consistiría en definir al mundo moderno (Estado, Ejército, Economía) como centro de la historia mundial. Pero jamás existió historia mundial hasta 1492, fecha fundacional del llamado "sistema-mundo" (Wallerstein). La coexistencia de muchos sistemas paralelos se configura como un solo sistema con la expansión portuguesa del siglo XV, que llega hasta el extremo oriente en el siglo XVI, y es con el descubrimiento de la América Hispánica que todo el planeta toma su lugar en una sola Historia Mundial. ¿Qué sucede en particular? España, como la primera Nación moderna, se configura con un Estado que unifica la península, con una Inquisición que genera por la fuerza el consenso nacional, con el poder militar que se le confiere conquista Granada (dominio musulmán), con el efecto unificador que provoca la edición de Gramática castellana de Nebrija en 1492 y con una Iglesia aliada al poder del Estado.

Con todas estas propiedades se abre la primera etapa de la "modernidad": el mercantilismo. Las minas de oro y plata de Potosí y Zacatecas en 1545, permiten acumular riqueza para rearmar un ejército capaz de vencer a los turcos en Lepanto en 1571. Con la introducción del mercantilismo y el descubrimiento del Nuevo Mundo, el Atlántico suplanta al Mediterráneo. De tal manera que la centralidad de la Europa Latina en la historia mundial es lo que determina el surgimiento de la modernidad; lo demás se va generando en torno a ello: la subjetividad, la propiedad privada, la libertad de contratos, etc. Entonces, el siglo XVII (con Descartes) ya es el resultado de un siglo y medio de modernidad; son efecto y no el punto de partida de la misma.

La revolución industrial del s. XVIII, tal como la llustración, son la segunda etapa de la modernidad, que amplían y profundizan lo iniciado ya en el siglo XV. Inglaterra sustituye a España como potencia hegemónica hasta 1945 y tiene el comando de la historia mundial desde el surgimiento del imperialismo de 1870.

El gran error del eurocentrismo europeo es haber confundido la universalidad abstracta con la mundialidad concreta. Aunque toda la cultura es etnocéntrica, esto debe ser revisado. El ego cogito moderno fue antecedido en más de un siglo por el ego conquiro (yo conquisto), que termina imponiendo su voluntad, que es la primera voluntad de poder. La conquista de México fue 
el primer ámbito del ego moderno. España tenía una evidente superioridad militar por sobre las culturas aztecas, mayas e incas -uso de las armas de guerra. Estratégicamente, la Europa moderna usará la conquista de Latinoamérica para obtener ventajas comparativas respecto de las culturas antagónicas vecinas. Su superioridad es, en buena medida, fruto de la experiencia, el conocimiento y la riqueza que obtiene de la conquista americana.

Sintetizando, la modernidad, como nuevo paradigma de vida cotidiana, de comprensión de la historia, de la ciencia, de la religión, emerge en el siglo XV con el dominio del Atlántico. Holanda, Francia, Inglaterra, son el fruto del siglo XVI, son el desarrollo resultante del camino abierto por España y Portugal. América Latina entra en la modernidad como la "otra cara", encubierta, dominada y explotada.

La modernidad, exteriormente, realiza un proceso completamente irracional, que oculta a sus propios ojos. Con ello, sus pretensiones de racionalidad interna se desploman. Dicho con otras palabras, por su contenido secundario y mítico, la modernidad es la justificación de una praxis irracional de la violencia. El mito tiene las siguientes propiedades:

a. La civilización moderna se autocomprende como la más desarrollada, superior.

b. La superioridad obliga a desarrollar a los más primitivos, rudos y bárbaros, y esto como una exigencia moral.

c. El camino educativo de desarrollo debe ser el seguido por Europa (surge la falacia desarrollista).

d. Si el bárbaro se opone al proceso civilizatorio, la praxis moderna debe ejercer la violencia necesariamente, para desmontar los obstáculos de tal modernización.

e. Si esta dominación produce víctimas, la violencia debe ser interpretada como un acto inevitable, y con un sentido ritual de sacrificio, en el que el héroe civilizador es el victimario de un sacrificio necesario.

f. Para el moderno, el bárbaro tiene la culpa: al oponerse el proceso civilizador, que significa su propia emancipación.

g. Se interpretan como inevitables los sacrificios de los pueblos inmaduros y más débiles.

La superación de la modernidad implica negar el mito de la misma. Debe emerger el rostro del Otro negado. Y debe emerger como Alteridad negada, sin voz ni cara. Debe quedar al descubierto la "otra-cara", oculta de la modernidad: el mundo periférico colonial, el indio sacrificado y esclavizado, la mujer oprimida, el niño y la cultura colonial enajenada.

3. Uno de los mitos más extendidos en la sociología se refiere al rol de ética protestante en la constitución del capitalismo europeo. En las líneas que siguen, abordaré éste argumento desde el rol del lujo en la configuración del capitalismo, y por razones de espacio, ponemos entre paréntesis la cuestión del papel del colonialismo. En su poco conocido libro Lujo y Capitalismo Werner Sombart formuló la antítesis de la hipótesis weberiana, sosteniendo que el lujo ha colaborado de muchas maneras a la génesis del capitalismo moderno, sobre todo por su fuerza generadora de mercados: "Esta fuerza puede considerarse del siguiente modo: Es sabido que toda empresa capitalista necesita, para poder vivir, un mínimum de ventas. La cuantía de esas ventas depende de dos circunstancias: la frecuencia de la circulación de las mercancías y la cuantía del valor de cambio de los objetos de circulación. La cuantía del valor de cambio de los objetos de 
circulación está determinada a su vez por dos factores: la cuantía del valor de cambio de las mercancías y por el gran número de mercancías" (Sombart 1979:118).

Ahora bien, en la historia de los pueblos europeos, concurren la necesidad de lo ordinario y la de lo delicado. Ambas tienen, en un principio, proporciones muy modestas; así, las ordinarias eran satisfechas en la aldea y se sostenían sobre bases locales, y las refinadas, cuando no se podían satisfacer autónomamente, dentro de las cortes señoriales o mediante el comercio remoto, eran cubiertas por artesanos. Se trata de demostrar cómo, de qué forma, las necesidades suntuarias desempeñaron un rol esencial en la génesis del capitalismo moderno.

a) En lo que respecta al comercio al por mayor, la lista de productos destinados al comercio suntuario es larga. Abarca los medicamentos, especias, perfumes y sustancias olorosas, materias colorantes, materias primas para la industria del tejido, artículos de adorno y telas para vestidos. Con las modificaciones en las rutas comerciales debido al descubrimiento del Nuevo Mundo, no sólo se expande el número sino también la cantidad de productos: el tabaco, el café, el té y el cacao, fueron, en la época de inicios del capitalismo, el monopolio de consumo de la gente de altos ingresos. Importante de señalar es que buena parte de la importaciones se pagaba con dinero obtenido por la explotación de las minas de oro y plata de las colonias americanas, de tal manera que el comercio interoceánico es hijo del lujo, un negocio centrado en la clase rica y pudiente, que vive exclusivamente del gasto suntuario, pues las mercancías importadas de ultramar eran de lujo.

De gran importancia también era el comercio de esclavos, un "artículo" de lujo proveniente de África y de los países musulmanes. La cantidad de esclavos "importados" a Europa, nada menos que en el siglo XIX, es impresionante. Así por ejemplo, se sabe que el número de esclavos venidos de las Antillas francesas fue de alrededor de 35.000, entre el año 1780 a 1789 (iaño de la Revolución Francesa!) (Sombart 1979:127).

Durante el siglo XVIII, el centro de importación de esclavos fue Inglaterra, y Liverpool en particular, donde en 1729-1751, se contaba con una flota de barcos dedicada exclusivamente al tráfico de esclavos, de tal manera que en 1751 se contabilizaban 35 embarcaciones (5.334 toneladas) destinadas a la caza de esclavos. Esto permite tener una somera idea de la demanda por ese entonces "producto de importación". Durante el siglo XVII y XVIII, el comercio internacional en Europa estuvo marcado por la importación de mercancías suntuarias. No obstante, uno tras otro, todos los países europeos, van configurando una industria de sustitución de importaciones. El primero fue Italia, luego Francia, Inglaterra, Holanda, Alemania, etc.

b) En lo que dice relación con el comercio al por menor, allí la influencia del lujo se nota con mayor claridad. Decae el tráfico del cobre y las legumbres (destinadas al consumo de los ejércitos) y crece el interés de los comerciantes por satisfacer las necesidades del lujo desmesuradamente, especialmente cuando el oro brasileño llena los bolsillos de los especuladores en Londres, París y Ámsterdam. Además, el comerciante de sedas, como el auténtico representante del comercio suntuario y de la ostentosa riqueza, tiene a la lady como consumidoras exclusivas; se expenden los artículos más costosos, ya que el comercio de sedas incluye además tejidos de oro y plata, brocateles, terciopelos y encajes. El comerciante de sedas es tanto almacenista y detallista. Después del gran incendio de Londres de 1666, el comercio suntuario al detalle se expande de tal 
manera que los lugares de venta debieron ser trasladados a la periferia de Londres, donde las calles eran más espaciosas "y la clientela distinguida, que venía en carruaje, incluso la corte, prefirió las tiendas nuevas a las viejas de la City" (Sombart 1979:133).

Este relato da cuenta del aumento del comercio suntuario exclusivo y cómo el espíritu del capitalismo en los siglos siguientes introduce el consumo suntuario más allá de los grandes centros urbanos. Todo esto sucede del modo siguiente: primero, al establecerse una clara distinción entre comercio al por mayor y al detalle, se opera una configuración monopólica incipiente, en cuyo contexto sólo unos pocos están en condiciones de seguir siendo almacenistas; segundo, los comerciantes comienzan a introducir mayor adorno y elegancia en sus establecimientos, a fin de agradar aún más a su clientela; tercero, los negocios por rama tienden a desaparecer, configurándose una mezcla creativa de ofertas a la venta. Los tapiceros en especial comienzan a vender ebanistería, espejos y toda suerte de objetos de lujo; cuarto, la objetivación de la relación entre comerciante y clientela, esencial para el desarrollo capitalista, comienza en las grandes tiendas de artículos de lujo; sexto, la amplitud de los negocios aumenta considerablemente, para lo cual hay suficiente evidencia empírica.

En síntesis, el comercio capitalista al detalle se desarrolla debido a la expansión del lujo. Más expresamente dicho: la naturaleza de las mercancías determina la forma de organización que el capitalismo asume; como las mercancías son de un alto valor, estaban destinadas a quien pudiera pagarlas. Por otro lado, la naturaleza de la clientela impulsa también el despliegue del capitalismo. Como las exigencias de una clientela distinguida generan exigencias cada vez mayores, y además nunca paga al contado, obliga al comerciante a desarrollar un sistema de créditos.

Pero es en la industria y la producción industrial donde con mayor notoriedad se percibe la influencia del lujo. Por industria de lujo se entiende aquella destinada a la satisfacción de necesidades suntuarias, y a ser bienes de uso individual, bienes de primer orden. El concepto es muy abarcante, pues involucra desde al brocatel y el terciopelo, hasta la fundición que produjo la tubería de hierro para las fuentes de Versalles. A continuación y por razones exclusivamente de espacio, vamos a enumerar los sectores productivos que abarcan:

(1) Industrias puras del lujo: se trata de aquellas que producen exclusivamente artículos de lujo: industria de la seda, industria de los encajes, fabricación de espejos, industria de la porcelana, industrias varias.

(2) Industrias mixtas: se trata de aquellas que producen no sólo objetos finos, sino objetos de fabricación burda: industria de la lana, industria del lienzo, industria de sastrería, industria del cuero, sombrerería, industria de la construcción, carretería y ebanistería.

Los efectos revolucionarios del lujo se remiten a la formación de un gran mercado interno, ejerciendo efectos indiscutibles en la estructura productiva de las sociedades capitalistas en proceso de configuración. El lujo, que le abre las puertas al capitalismo, haciendo ingresar al mercado productivo a la industria dedicada a este rubro. Las causas, a juicio de Sombart, son en lo esencial dos: La primera se refiere a la naturaleza del proceso productivo, pues el artículo de lujo requiere casi siempre de una materia de alto valor, que con frecuencia tiene que venir de los países coloniales y del Nuevo Mundo. Por otro lado, el procedimiento con el que el artículo se 
produce, es más costoso que el artículo corriente. Los ejemplos sobran y van desde la incipiente industria textil lujosa, hasta la fabricación del cristal y la porcelana. La segunda causa que hace que la industria de lujo esté antes que las demás en el régimen de circulación de mercancías, reside en la naturaleza del despacho. La venta de los productos de lujo está sujeta a más contingencia que la de los artículos corrientes, ya que la demanda en extremo dinámica, debido que los caprichos de los ricos, cambian rápidamente según se trate de la moda en boga. Los rápidos cambios concitan con frecuencia un exceso de exigencias y un esfuerzo por satisfacerlas. Por esto, el productor debe ser extraordinariamente flexible para acomodar su producción a dichas exigencias cambiantes.

La superioridad del libro de Sombart reside en que todos sus argumentos, salvo expresa advertencia, están apoyados por datos empíricos, mientras que la tesis del rol de la ética protestante no posee fundamentación empírica alguna. Pero por sobre todo, la conclusión es en extremo insólita: aparentemente, el capitalismo no necesitó de ética alguna (ni protestante ni católica) para desplegarse como modo de producción y forma de vida, como sostuvo Engels y Simmel en la Filosofía del Dinero. Y por lo tanto, la aseveración de Weber (1969:71) que sostiene "el tipo-ideal del empresario capitalista, encarnado en algunos nobles ejemplares, nada tiene que ver con este tipo vulgar o afinado del ricachón. Aquél aborrece la ostentación, el lujo inútil y el goce consciente de su poder; le repugna aceptar los signos externos del respeto social de que disfruta porque le son incómodos. Su comportamiento presenta más bien rasgos ascéticos", resulta ser claramente no sólo errónea, sino ingenua y falaz.

La ética es y seguirá siendo el paradigma perdido de la modernidad, pues el despliegue de ningún sistema funcional ha necesitado jamás de ella para imponerse y estabilizarse (Luhmann). Por otra parte, considerando los discursos de Alberti, Defoe y Franklin, comentados por Sombart en "EI Burgués", sus opiniones no resultan creíbles en el burgués de viejo estilo. Porque sus veredictos de que la riqueza no constituía un fin sino el medio para el logro de fines "superiores", cuáles eran el prestigio y la independencia, solo pueden sostenerse si la maximización del lucro ha conseguido tal nivel de estabilidad (permitiendo en lujo suntuario), que permita tales "lujos" como retirarse lo más pronto posible de los negocios (Sombart 1993:163).

¿Cómo es posible que una cierta sociología se haya dejado embaucar por tanto tiempo por una tesis tan poco plausible de veracidad? Es una interrogante que por razones de espacio no ponemos desarrollar in extenso en este lugar. Agregaremos solamente dos argumentos a los anteriores:

(a) El primero de ellos explica la existencia del lujo en la configuración del capitalismo, debido una nueva codificación del amor, imponiendo el principio de la "ilegitimidad" en las relaciones sexuales y matrimoniales desde finales de época medieval. Principalmente en Francia, pero también y originalmente en Italia, se lleva la vida amorosa hasta un refinamiento y dedicación jamás visto hasta que finalmente el siglo XVIII, culmina con la institucionalización de la cortesana (Elias 1996:285).

Cuando el amor libre se introduce en la sociedad, coexistiendo con el amor matrimonial, las mujeres que practican aquél son o las jóvenes de buena familia que se han dejado seducir, o las esposas adúlteras y las meretrices. Desde este instante hasta fines de nuestra época, las relaciones del amor libre, antes y después del matrimonio, fueron siempre en aumento, llegando a constituir 
el complemento ideal al matrimonio. Londres y París, que a fines del siglo XVIII, no tenían más de 100.000 habitantes respectivamente, contaban sin embargo con 50.000 y 30.000 meretrices respectivamente (Sombart 1979:55).

La innovación comienza a gestarse en el Renacimiento, permitiendo que los príncipes tuvieran concubinas, pero siempre las habían tenido, pero lo nuevo es que las jóvenes de la burguesía compartían también esta práctica. En Francia, donde las amadas reales comienzan a dominar el mundo, ennobleciendo a todas las sacerdotisas del amor, las relaciones del amor ilegítimo quedaron limpias de toda lacra. Pero como la influencia de la vida cortesana era enorme y toda la burguesía trataba de emular sus prácticas, se generalizó la legitimidad de la ilegitimidad en toda la sociedad.

Ya no se necesitaba pertenecer a la corte para ser femme entretenue o cocotte. Este tipo de cortesana que no lo es en sentido estricto, se expande por la sociedad y emerge también en las ciudades italianas como Roma y Venecia, donde las condiciones eran favorables a la emergencia de un nuevo tipo de mujer, amante del lujo y fuerza motriz de la demanda de artículos suntuarios. Obviamente también había industriales y comerciantes capitalistas que observaban horrorizados el surgimiento y la generalización de la cortesana. Para la formación de la cortesana moderna fue importante que ya desde el siglo XVII las mujeres aparecieran en los teatros de París, pero es definitivamente durante el siglo XVIII que se generaliza la costumbre de tener a una mujer elegante junta, o en lugar de la propia esposa. La historia de la galantería y de la consiguiente coquetería es, pues, durante el siglo XVIII, un paso importante en la configuración de la nueva identidad de la mujer moderna, como apuntan Simmel (1988:89) y Luhmann (1985:72).

El rol importante que desempeñaban estas mujeres lo revela la publicación de un anuario o libros de señas de las principales cocottes, libros en los que aparecían su rostro, su tipo y sus principales actitudes. El ascenso de la cortesana elegante contribuye también a la formación del gusto de la mujer honesta, vale decir, que las mujeres de influencia son influenciadas por el gusto de la cocotte.

(b) A juicio de Bruno Latour, uno de los exponentes de la novedosa teoría del actor-red, el relato sociológico de Weber no sólo es impreciso, sino que repite un imaginario que obedece al importexport, de las dos grandes divisiones. En su maravilloso libro Nunca Fuimos Modernos, señala lo siguiente: "Nosotros, los occidentales, somos absolutamente diferentes de los 'otros', ése es el grito de victoria o la larga queja de los modernos. La Gran División entre Nosotros, los occidentales, y Ellos, el resto, desde los mares de China hasta Yucatán, desde los esquimales hasta los aborígenes de Tasmania, no dejó de obsesionarnos. No importa qué hagan, los occidentales traen la historia en los cascos de sus carabelas, y sus cañoneras, en los cilindros de sus telescopios y en los émbolos de sus jeringas para vacunar. Ellos llevan una carga del hombre blanco a veces como una tarea exaltante, a veces como una tragedia, pero siempre como un destino. No pretenden sólo que difieren de los otros como los sioux o los algonquinos, o de los baoules de los lapones, sino que difieren de una manera radical, absoluta, hasta el punto de que puede ponerse de un lado la cultura occidental y, del otro, el resto de las culturas, porque todas tienen en común el ser justamente culturas entre otras. Occidente, y sólo él, no sería una cultura, no sólo una cultura. ¿Por qué Occidente piensa así? ¿Por qué él y sólo él no sería solamente una cultura? Para comprender la profundidad de esa Gran División entre Ellos y Nosotros hay que volver a esa otra 
Gran División entre los humanos y los no humanos...Nosotros los occidentales no podemos ser una cultura entre otras porque también movilizamos la naturaleza. No, como lo hacen las otras sociedades, una imagen o una representación simbólica de la naturaleza, sino la naturaleza tal y como es, o por lo menos tal y como las ciencias la conocen, ciencias que permanecen en las sombras, inestudiables, inestudiadas" (Latour 2007:144).

Pero la teoría del actor-red va más allá y borra todas las diferencias que suponemos que existen entre los humanos y los no-humanos, máquinas, ascensores, computadores, lavadoras, con lo que se ubica en "el lado de enfrente" de todas las teorías universalistas de la modernidad. Es cierto que ella no está interesada en lo más mínimo en inventar una teoría de la modernidad. Pero no importa, porque en ese cometido no está sola: la acompañan la etnometodología en todas sus expresiones, desde Harold Garfinkel hasta Jörg Bergmann y Lucy Suchman, la sociología de Erving Goffman y sus discípulos, y el interaccionismo simbólico desde Herbert Blumer hasta Norman Denzin.

Para aquellos que gustan buscar ancestros venerables que coronen el origen de la disciplina sociológica, la disputa entre Gabriel Tarde, el mayor, y Emile Durkheim, el ganador, significó el olvido definitivo del perdedor; pero si la batalla entre ambos hubiese tenido un desenlace diferente, la sociología habría seguido caminos muy distintos a los conocidos. De igual manera, la popularidad alcanzada por una tesis tan empíricamente débil como la ética protestante como "primer motor" del capitalismo, sostenida por el indiscutible ganador, Max Weber, ensombreció una figura menor, la de Werner Sombart, el perdedor; de seguro que si hubiese sido al revés, todas las cosas hubiesen sido diferentes y mejores para una sociología sin pretensiones universalistas.

Walter Benjamin, en su opúsculo póstumo denominado El capitalismo como religión, señala que la forma de producción capitalista es en sí una religión pero que no conoce ninguna teología que le sea propia. Además, "el capitalismo se ha desarrollado en Occidente -como se puede demostrar no sólo en el calvinismo, sino en el resto de las orientaciones cristianas ortodoxasparasitariamente respecto del cristianismo, de modo tal que, al final, su historia es en lo esencial la de su parásito, el capitalismo"(Benjamin 1991:100). La comprobación de esta estructura religiosa del capitalismo nos lleva a observarlo no como forma condicionada por la religión, como pensaba Max Weber, sino como un fenómeno que debe ser entendido como religioso, pero carente de toda teología.

Y Karl Marx relata cómo la fuerza de las luchas obreras dio origen a una reducción en la jornada de trabajo y cuáles son las repercusiones que se constatan en otros países. Pero Marx, que por supuesto no pudo leer a Weber, nos señala respecto de la acumulación originaria de capital, lo siguiente: "Los orígenes de la acumulación primitiva pretenden explicarse relatándolos como una anécdota del pasado. En tiempos muy remotos -se nos dice- había, de una parte, una minoría trabajadora, inteligente y sobre todo ahorrativa, y de otra parte un tropel de descamisados, haraganes, que derrochaban cuanto tenían y aún más... Así se explica que mientras los primeros acumulaban riqueza, los segundos acabaron por no tener ya nada que vender más que su pelleja. De este pecado original arranca la pobreza de la gran mayoría...y la riqueza de una minoría, riqueza que no deja de crecer, aunque haga ya muchísimo tiempo que sus propietarios han dejado 
de trabajar" (Marx 1975:601). Los que aún siguen creyendo en éstas niñerías insubstanciales, harían bien en leer el capítulo XXIV del primer libro de EI Capital.

\section{Jürgen Habermas y el apogeo errático del proyecto de modernidad "inconclusa": "mundo de la vida" y "sistema" en los intersticios de la praxis de la sociedad occidental}

La teoría y principalmente el diagnóstico de la modernidad de Jürgen Habermas, se fundamenta en una reconstrucción de la teoría clásica europea y en aproximación y crítica a la obra de Marx, Weber, Mead, Durkheim, Lukács, Adorno y Parsons. Pero la estrategia de Habermas, al alero de la teoría de la acción social, supera con creces la obra de los autores antes mencionados, procurando ser además una teoría de la sociedad moderna. Al concebir la modernidad como un continuo permanente e indisoluble de diferenciación, el esfuerzo teórico se ubica sin embargo principalmente en la cercanías de Parsons y Weber, a quienes les dedica un espacio privilegiado en su teoría de la acción comunicativa, publicada en alemán en 1981 y traducida al español en 1987.

En el nivel de arquitectura teórica, referida tanto a la teoría social como al diagnóstico de la sociedad, la teoría de la acción comunicativa propone una distinción basal, la distinción entre el "sistema" o integración sistémica (acción estratégica) orientada hacia el éxito y el "mundo de la vida" o integración social entre, orientada hacia en el entendimiento intersubjetivo (Habermas 1987:161).

A esta distinción, que se encuentra presente en otras obras anteriores, le atribuye Habermas distintos tipos correspondientes de acción: el mundo de la vida, que el autor dice reconstruir y modificar desde la versión de Husserl, es el ámbito de la reproducción simbólica ubicada en el entendimiento intersubjetivo orientado a la acción comunicativa. El "sistema", en cambio, es la esfera atribuida a la acción estratégica, orientada hacia el éxito guiado por la acción social con arreglo a fines y metas.

La distinción entre sistema y mundo de la vida es el núcleo gravitante de la totalidad de la argumentación referida a la acción comunicativa, pero también al análisis sistémico. Al concebir Habermas la evolución social como un proceso de diferenciación de "segundo orden", procura esclarecer la distinción anterior: "Sistema y mundo de la vida no sólo se diferencian internamente como sistema y mundo de la vida, sino que también se diferencian simultáneamente el uno del otro. En sociología se ha vuelto convencional distinguir entre las etapas socio-evolutivas que representan las sociedades primitivas, las sociedades tradicionales o estamentalmente organizadas y las sociedades modernas (con un sistema económico diferenciado). Bajo aspectos sistémicos éstas etapas pueden caracterizarse por los nuevos aspectos sistémicos que en ellas se presentan y por los niveles de complejidad que estos mecanismos comportan. En este plano analítico, es decir, en el plano del análisis sistémico el desacoplamiento de sistema y mundo de la vida se refleja como sigue: el mundo de la vida que al principio es coextensivo con un sistema social poco diferenciado, se va degradando progresivamente a un subsistema entre otros. En ese proceso los mecanismos sistémicos de desligan cada vez más de las estructuras sociales a través de las cuales se cumple la integración social. Las sociedades modernas alcanzan, como veremos, un nivel de diferenciación sistémica en que la conexión entre organizaciones se ha vuelto autónoma quedando establecida a través de medios de comunicación deslingüistizados. Estos medios de comunicación controlan un comercio social ampliamente descolgado de normas y 
valores, es decir, a aquellos subsistemas de acción económica y administrativa racionales con arreglo a fines según el diagnóstico de Max Weber se han independizado de sus fundamentos práctico-morales. Pero, al mismo tiempo, el mundo de la vida es el subsistema que define la consistencia (Bestand) del sistema social en su conjunto" (Habermas 1987:216).

Como vemos, la tesis del desacoplamiento del sistema y el mundo de la vida configura la piedra angular de la teoría de la acción comunicativa; con todo detalle en las páginas siguientes, expone el procedimiento de su desacoplamiento (Habermas 1987:219 ss.) y presentándolo tanto como el resultado de la diferenciación del sistema y el mundo de la vida así como de procesos de diferenciación endógenos en el sistema y en el mundo de la vida. Para ello, Habermas utiliza el concepto de aumento de complejidad sistémica y de acrecentamiento de racionalización del mundo de la vida respectivamente, graficando la evolución de ambos dispositivos. De tal manera que al acrecentamiento de complejidad en el sistema correspondería una creciente racionalización en el mundo de la vida. El complejo de relaciones que caracterizan los vínculos de interdependencia entre los dos procesos, es expuesto por Habermas, en una estructuración secuencial, que pasamos a exponer a continuación:

(1) El fundamento histórico para el concepto de mundo de la vida es identificado por Habermas en las sociedades arcaicas. "Donde más apoyo empírico encuentra el concepto de sociedad como mundo de la vida es en sociedades arcaicas, en donde las estructuras de interacciones lingüísticamente mediadas regidas por normas constituyen a la vez las estructuras sociales sustentadas" (Habermas 1987:219). Es decir, en la concepción habermasiana, el mundo de la vida, de principio a fin y todos los plexos de linealidad histórica, está regidos y tutelados por normas, detrás de las cuales subyacen (se supone) valores comunes e intersubjetivamente compartidos. Esto se escalece notablemente en la exposición de su teoría de la evolución social, cuando se refiere al "materialismo histórico y el desarrollo de las estructuras normativas" (Habermas 1981:9 ss; 131-242).

(2) En las antiguas sociedades, sistema y mundo de la vida se conjugan y condicionan mutuamente, consolidándose en una sola unidad. "En el intercambio de mujeres normado por reglas de matrimonio, coinciden integración social e integración sistémica. Y otro tanto cabe decir sobre el mecanismo de formación de poder. Opera dentro de dimensiones de sexo, generación y descendencia fijadas por el sistema de parentesco y sólo permite diferenciaciones de estatus basadas en el prestigio, mas no en la posesión de poder político" (Habermas 1987:231). Vale decir, el proceso de acoplamiento y concomitancia entre sistema y mundo de la vida es observable sólo en sociedades arcaicas.

(3) En el curso de la evolución social, la integración social y la integración sistémica comienzan a separarse paulatinamente. "Pero los mecanismos que sirven al aumento de la complejidad sistémica no están armonizados a priori con los mecanismos que, a través del consenso normativo y del entendimiento lingüístico, cuidan de la cohesión social del colectivo. Los mecanismos sistémicos sólo pueden permanecer íntimamente ensamblados con los mecanismos de la integración social mientras permanezcan adheridos a estructuras sociales previamente dadas, esto es, al sistema de parentesco. Pero en cuanto se forma un poder político ya no obtiene su autoridad del prestigio de los grupos de descendencia dominantes...El poder que se constituye 
ahora en el plano de la organización política se convierte en el núcleo de cristalización de una nueva institución: del Estado" (Habermas 1987:233).

Además, desde la aparición del Estado, con la introducción generalizada del medio dinero en los procesos de intercambio, se complementa con las instituciones de la economía, por lo que el Estado comparativamente moderno debe orientarse hacia ella.

(4) La evolución social, entendida como aumento de la complejidad sistémica (mediante la diferenciación en subsistemas parciales, en cuyo contexto el todo se subdivide en partes), será percibida en la forma de nuevas formas de institucionalización, desde la perspectiva endógena de los habitantes afectados del mundo de la vida. Por lo que la circulación del medio dinero en los procesos de intercambio, transforman a la sociedad en gradualmente moderna. "Estos plexos funcionales, desligados de los contextos normativos y que se independizan formando subsistemas, constituyen un desafío para la capacidad de asimilación del mundo de la vida. Se coagulan en una segunda naturaleza, en una sociedad vacía de contenido normativo, que nos sale al paso como algo en el mundo objetivo, como un fragmento de vida social objetivada. El desacoplamiento de sistema y mundo de la vida se refleja en el seno de los mundos de la vida modernos, por de pronto como objetivación (Versachlichung): el sistema social rompe definitivamente el horizonte del mundo de la vida, se sustrae a la pre-compresión de la práctica comunicativa cotidiana y sólo resulta accesible al saber contra-intuitivo de las ciencias sociales que comienzan a emerger en el siglo XIX.Y lo que ya hemos obtenido desde la perspectiva de la teoría de sistemas, es decir, desde la perspectiva externa, tiene, a lo que parece, todos los visos de configurarse desde la perspectiva interna: cuando más complejos se vuelven los sistemas sociales, tanto más provincianos se tornan los mundos de la vida. En un sistema social diferenciado, el mundo de la vida se encoge, y se convierte en un subsistema más" (Habermas 1987:244).

En buenas cuentas, la elevación del nivel de complejidad conduce "a un nuevo nivel de diferenciación sistémica (que) exige reestructuraciones en el ámbito nuclear que constituyen las instituciones encargadas de la regulación jurídico-moral, esto es, de la regulación consensual de los conflictos de acción" (Habermas 1987:245), con lo que la moral y el derecho también se complejizan. Habermas expone consumo detalle cómo el despliegue de la moral (de preconvencional, a convencional y postconvencional) y la diferenciación del derecho (derecho penal, derecho civil, derecho público) expanden respectivamente sus ámbitos de diferenciación: "Entiendo esta relación en el sentido de que sólo pueden establecerse nuevos niveles de diferenciación sistémica cuando la racionalización del mundo de la vida ha alcanzado un nivel correspondiente" (Habermas 1987:253). Pero sin duda que lo más relevante del citado anterior, es que el aumento de complejidad sistémica y la progresiva e ineluctable formación de subsistemas parciales, produce un detrimento en el mundo de la vida. Lo diabólico de la diferenciación sistémica se traduce en un empobrecimiento sistemático del mundo de la vida. Si operamos, con un ápice de imaginación, desde lo que Habermas llama "perspectiva interna" y consideramos al mundo de la vida como un sistema y al sistema como su entorno, tenemos ante nuestra vista un caso típico del efecto destructivo de un entorno sobre el sistema, descrito por Maturana y asumido más posteriormente por Luhmann.

(5)El quinto paso es algo nebuloso y contradictorio. Habermas postula, por un lado, una creciente racionalización (siempre normativa) del mundo de la vida (pero racionalización en el sentido del 
logro de metas de entendimiento comunicativo en lugar del mero acatamiento de normas de conducta), pero por otro lado una distorsión de esa racionalización mediante los sistemas, que por su nulo acoplamiento al lenguaje, operan divorciados de toda actividad orientada hacia el entendimiento. "La racionalización del mundo de la vida puede ser concebida como una progresiva liberación del potencial de racionalidad que la acción comunicativa lleva en su seno. Con ello, la acción orientada al entendimiento adquiere una autonomía cada vez mayor frente a los contextos normativos, pero simultáneamente el mecanismo de entendimiento, cada vez más sobrecargado y finalmente desbordado, es sustituido por medios de comunicación desligüistizados" (Habermas 1987:219).

Al parecer aquí hay implicadas dos cuestiones: (a) que en el mundo de la vida la comunicación orientada hacia el entendimiento acaece progresivamente con mayor fuerza e independencia de las directrices normativas, cuestión que se consigue mediante la práctica de una moral postconvencional; (b) que el sistema recurre, para su expansión, a la acción comunicativa orientada hacia el entendimiento, cuestión que a simple vista se presenta como una gigantesca paradoja, pues el proceso de diferenciación sistémica no puede usar recursos que no le pertenecen ni le incumben, y que además no necesita. Habermas procura salir de la paradoja postulando una suerte de omnipotencia del sistema sobre el mundo de la vida. Pero dicha recurrencia, señala Habermas, es inmensamente costosa, por lo que será sustituida por el sistema por dos "medios direccionales de control" (a-lingüísticos). Ellos son el dinero y el poder: "Medios como el dinero y el poder arrancan de vinculaciones cuya motivación es empírica; codifican un trato 'racional con arreglo a fines' con masas de valor susceptibles de cálculo y posibilitan el ejercicio de una influencia estratégica generalizada en la decisiones de los otros participantes en la interacción en un movimiento de elusión y rodeo de los procesos de formación lingüística del consenso. Como no solamente simplifican la comunicación lingüística sino que la sustituyen por una generalización simbólica de perjuicios y resarcimientos, el contexto del mundo de la vida en el que siempre están insertos los procesos de entendimiento queda desvalorizado y sometido a las interacciones regidas por medios: el mundo de la vida ya no es necesario para la coordinación de acciones" (Habermas 1987:259).

El efecto es catastrófico, pues el mundo de la vida se convierte en tangencial y se tecnifica. Aún más, es colonizado. "Los subsistemas sociales que se diferencian a través de tales medios pueden independizarse frente a un mundo de la vida reducido a entorno del sistema. De ahí que desde la perspectiva del mundo de la vida este asentamiento de la acción sobre medios de control aparezca, lo mismo como un alivio a la necesidad de comunicación y una reducción de los riesgos que la comunicación comparta, que como un condicionamiento de las decisiones en un espacio de contingencias ampliado, y en este sentido como una tecnificación del mundo de la vida" (Habermas 1987:259).

Es imposible continuar con la exposición de la teoría de Habermas, sin hacer referencia a sus debilidades e imperfecciones, las que a continuación pasamos a exponer:

1. La distinción central de la teoría, "sistema" y "mundo de la vida", es suficientemente abstracta y omniabarcante, pero paga un precio demasiado alto por el logro de un nivel de ensimismamiento tan elevado. En efecto, ésta distinción a lo largo de las complejas cadenas argumentativas, se convierte en progresivamente dicotómica y unilateral. Sobre todo, por el carácter todopoderoso 
que presuntamente tiene el sistema sobre el mundo de la vida, cuyas consecuencias son valoradas por Habermas como eminentemente perniciosas, destructivas, tecnificantes y colonizadoras, aparte de inevitables e inherentes a la lógica de la evolución social. Sin embargo, la trasferencia de plexos de influjo desde el mundo de la vida hacia el sistema, son completamente desatendidos en la argumentación habermasiana, considerándolas simplemente como inexistentes.

Y desde la óptica de la arquitectura teórica, con toda razón, pues la reespecificación que Habermas hace de la noción de "mundo de la vida", uno de los productos y descubrimientos más importantes para las ciencias sociales, gracias a la perspicacia y rigurosidad de Edmund Husserl, es equivocada, regresiva y desafortunada. Este es el tema del punto siguiente.

2. Habermas trata de compatibilizar el concepto de mundo de la vida (desde la obra principalmente de Schütz, justamente el menos indicado para ser criticado) con su teoría de la acción comunicativa, afirmando que la consecución del entendimiento, principio axial de la teoría, significa al fin de cuentas la obtención de un acuerdo entre los participantes en la comunicación acerca de la validez de una emisión; este acuerdo impone el reconocimiento intersubjetivo de las pretensiones de validez que un hablante vincula con ella. El consenso no puede lograrse si, por ejemplo, un oyente acepta la verdad de la afirmación, pero pone en duda la veracidad del otro o la adecuación normativa de la emisión (Habermas1987:171).

Igual cosa sucede si un oyente acepta la validez normativa de un mandato, pero pone en duda la seriedad del deseo del mismo. En el ejemplo que Habermas pone a continuación, el de un grupo de trabajadores de construcción a la búsqueda de cerveza, son de una importancia gravitante las jerarquías informales de los trabajadores ocupados en la obra, que configuran el marco normativo en el que uno puede exigir a otro que haga algo. De cierta forma, el mundo de la vida, está siempre presente en el trasfondo de cualquier contexto. En cuanto plexo de remisiones se incluye en la situación, pero en cuanto componente de la situación pierde su trivialidad y solidez incuestionada. Efectivamente, si los elementos de una situación se convierten en relevantes, determinadas autoevidencias pueden ser movilizadas en la forma de un saber sobre el cual existe consenso y que simultáneamente es posible de problematizar.

Todos estos aspectos ya fueron resueltos por Schütz y su teoría de la relevancia (Schütz 1971, Schütz y Luckmann 2003:182 ss.), con la salvedad que Schütz no estaba interesado en el logro de consensos, sino en la fundamentación general de una sociología fenomenológica de la "actitud natural" mundana, profana, ordinaria, más allá de la filosofía trascendental de Husserl, a quien le reprocha (a) no haber resuelto satisfactoriamente el problema de la intersubjetividad y (b) confiar acríticamente en el método de la reducción fenomenológica (epojé), que Schütz rechaza categóricamente. Schütz busca soporte en una redefinición exitosa de los tipos ideales de Weber, cuya mutación en tipos mundanos, los llamados "tipos constitutivos" (Husserl 1993: 145 ss, Schütz 1995: 162 ss.), ofrecen uno de los pilares sobre los cuales 20años más tarde Harold Garfinkel construirá una praxeología del mundo social cotidiano, ampliamente conocida como etnometodología (Garfinkel 2006).

Pero volvamos a Habermas. Según él, el concepto de acción comunicativa tiene que ver con dos tipos de situaciones: (a) con el aspecto teleológico de la realización de fines (o con la ejecución de planes de acción) y (b) con el aspecto comunicativo de interpretación de la situación y la obtención 
de un acuerdo. Habermas sostiene que los participantes en la comunicación persiguen de común acuerdo, buscar coherencia entre sus planes de acción, vale decir, el logro del entendimiento intersubjetivo. Habermas está tan atado a un acercamiento lo más intenso a la "situación ideal de la comunicación", que sostiene que los participantes en la comunicación definen una situación en común y tratan con o sin éxito, dos riesgos: (a) que el entendimiento fracase y (b) que el plan de acción se malogre (Habermas 1987:181) y todo se desmorone. Nada más lejano del proyecto de Schütz y a años luz de praxeología de las acciones rutinarias que tematiza la etnometodología.

Cuando Habermas argumenta que "Schütz adopta una posición ambivalente en el campo de tensiones entre análisis fenomenológico del mundo de la vida y teoría de la acción social" (Habermas 1987:185), falta a la verdad o simplemente se equivoca. En el intercambio epistolar entre Schütz y Parsons (entre 1940 y 1956), Schütz se distancia claramente de Parsons, principalmente en dos aspectos: (a) en el atamiento a normas de valor que posee la totalidad de la teoría de la acción social funcionalista (Schütz y Parsons 1977:46 ss.) solicitando mayores explicaciones, las que obviamente Parsons nunca entregó; (b) en relación a la pregunta por la "perspectiva subjetiva" de la teoría parsoniana de la acción social, que como sabemos jugaba para Schütz un rol decisivo en la interpretación de la acción social; al respecto, el desinterés de Parsons es suficientemente conocido (Schütz y Parsons 1977:72 ss.). Por ello es que Schütz busca sustento en Weber respecto de una solución metodológica para la construcción de los tipos ideales. Su postura es diáfana: la aproximación a Weber es sumamente crítica, y la reformulación de Schütz respecto de los tipos ideales es tan radical como diferente a la metodología de Weber (Schütz 1993:205-234).

En seguida, argumenta Habermas que Schütz "no aprehende las estructuras del mundo de la vida recurriendo directamente a las estructuras de la intersubjetividad lingüísticamente generada, sino al reflejo de esas estructuras en las vivencias subjetivas de un actor solitario" (Habermas 1987:185). En este sentido, Habermas ignora que Schütz resolvió elegantemente y a la usanza fenomenológica el problema de la intersubjetividad, en su conocida tesis general de la reciprocidad de las perspectivas. Esta tesis se basa en las idealizaciones de Husserl, sustento del a priori pre-teórico de la actitud del sujeto cognoscente en el mundo de la vida, pero Schütz da un vuelco mundano a las idealizaciones, por ello es que la Tesis posee dos sub-tesis:

(a) la idealización de la intercambiabilidad de puntos de vista, en la cual alter hace como-si intercambiara su punto de observación con alter, no cayendo, sin embargo, en la fábula de la empatía, que Schütz rechaza terminantemente;

(b) la idealización de la congruencia de los sistemas de relevancia, en la cual ego y alter se comportan como-si la atencionalidad de la conciencia se centrara, en un esquema tema-horizonte, en el mismo objeto temático. (Schütz 1995:282).

Mientas que la intersubjetidad para Habermas se consigue con el logro de consensos contrafácticos -una solución tan superficial como ingenua- para Schütz la intersujetividad sólo puede ser una representación mundana, por ello la Tesis toma distancia de toda argumentación trascendental. 
Pasamos por alto los siguientes argumentos de Habermas respecto de Schütz, pues sólo dejan en claro un desconocimiento de su obra, en especial de su teoría de la relevancia, para concentrarnos en los argumentos centrales de su redefinición. Habermas, al tildar de culturalista la teoría de Schütz respecto del mundo de la vida ofrece como alternativa una redefinición de raigambre normativista: "también las solidaridades de los grupos integrados a través de valores y normas y las competencias de los individuos socializados penetran a ergo en la acción comunicativa, entonces es menester corregir la reducción culturalista del concepto de mundo de la vida" (Habermas 1987:193).

Para ello, Habermas reconoce la incapacidad del concepto de mundo de la vida enmarcado en la teoría de la acción comunicativa, para el abordaje teórico de los fenómenos cotidianos. Pero en la práctica cotidiana los participantes en la interacción realizan también exposiciones narrativas de lo que les acontece, en cuyo contexto introducen descripciones de sucesos socioculturales; el carácter profano del saber que ponen de manifiesto, no es nada novedoso. Ya la etnometodología ha problematizado e investigado suficientemente estas formas comunicativas mayores, y el análisis conversacional las ha puesto bajo la lupa del razonamiento práctico en ellos contenido, poniendo de manifiesto la fecundidad de una praxeología del "narrar historias". La sobrevaloración que les atribuye Habermas a este tipo de estudios es trivial e impropia: por supuesto que los relatos que los hablantes ejecutan aprovechando la oralidad del discurso cotidiano permite hacer enunciados acerca de la reproducción de mundos de la vida, cuya estructura es comunicativa, pero praxeológicamente y profanamente comunicativa y no "habermasianamente" comunicativa (Habermas 1987:197).

Habermas sostiene que bajo el aspecto funcional del entendimiento, la acción comunicativa sirve a la conservación de la tradición y a su renovación; bajo el aspecto de la coordinación de la acción, a la coordinación social y a la creación de solidaridad; bajo el aspecto de la socialización, a la formación de identidades personales. De ésta manera se reproducen las estructuras simbólicas, es decir, por la vía del saber válido, de la estabilización de la solidaridad y de la formación de actores capaces de responder por sus acciones (Habermas 1987:196). Con toda franqueza, me es imposible identificar el sustento teórico que las afirmaciones anteriores encierran. No resulta plausible que la narración de historias, por muy verdaderas que sean, generen integración y solidaridad. Que las narraciones conservan y renuevan tradiciones es una verdad de Perogrullo, pero que contribuyan a la formación de identidades vía socialización, me parece francamente una ridiculez.

Pero la sorpresa es mayor cuando Habermas afirma que "a estos procesos de reproducción material, integración social y socialización corresponden los componentes estructurales del mundo de la vida que son la cultura, la sociedad y la personalidad" (Habermas 1987:196). A estas alturas, uno se pregunta si es Habermas quien argumenta, o Parsons por boca del susodicho porque el modelo estructural de mundo de la vida habermasiano es idéntico a la concepción de "sistema social" que Parsons desarrolla, sólo que Parsons le agrega el prefijo de "sistemas". En seguida, sobrevienen las definiciones correspondientes: "Llamo cultura al acervo de saber, en que los participantes en la comunicación se abastecen de interpretaciones para entenderse sobre algo en el mundo. Llamo sociedad a las ordenaciones legítimas a través de las cuales los participantes en la interacción regulan sus pertenencias a los grupos sociales, asegurando con ello la solidaridad. Y por personalidad entiendo las competencias que convierten a un sujeto en capaz de lenguaje y de 
acción, esto es, que lo capacitan para tomar parte en los procesos de entendimiento y para afirmar en ellos su propia identidad" (Habermas 1987:196).

Independientemente de las semejanzas exageradas de los componentes del mundo de la vida habermasianos con lo que Habermas llama el concepto "culturalista" del mundo de la vida, me interesa especialmente destacar el indudable componente normativo de cada uno de éstos dispositivos. Así, el saber cultural que penetra en las definiciones de la situación tiene que ser testeado, es decir, tiene que validarse frente a las normas, hechos y vivencias, de tal manera que la reproducción del mundo de la vida consistiría en la prosecución y renovación de la tradición, reiterándola o bien rompiendo con ella. Es decir, el mecanismo de reproducción es idéntico al concepto de semántica desarrollado por Luhmann, entendido como el patrimonio cultural de una sociedad que oscila entre comunicación y sentido, poniendo a disposición los temas conversables en la interacción (Luhmann 1998:9-72), con la diferencia que Luhmann prescinde de cualquier determinación normativa. Para Habermas, la continuidad y la coherencia de estas semánticas tienen su medida en la racionalidad del saber aceptado como valido (Habermas 1987:200).

Además, si se trata de una sociedad suficientemente integrada, las coordinaciones se balancean entre los componentes de los mundos de la vida menos integrados con los de la integración de los otros dos dispositivos. Esto consiste, por un lado, en la pertenencia de individuos a grupos legítimamente regulados y por otro, en vínculos de carácter moral u obligaciones morales.

Por lo tanto el núcleo de valores culturales se institucionaliza en ordenamientos legítimos y queda incorporado a una realidad normativa lo suficientemente resistente como para hacer que el núcleo de valores se sustraiga al test permanente de la acción orientada al entendimiento. Y el rol de la socialización consiste en el mantenimiento de los otros dos componentes (la sociedad y la cultura), es decir, en las interpretaciones que los individuos producen y en motivaciones para actuar en conformidad con las normas (Habermas 1987:201).

Con la decisión de normativizar cada uno de los vértices del mundo de la vida, Habermas comete un gigantesco auto-sabotaje. Para decirlo con la aguda y perspicaz sentencia de Garfinkel, lo hace convirtiendo a los habitantes con su concepto de mundo de la vida en simples estúpidos culturales (Garfinkel 2006:82). Aún más, los reproches de Habermas de "culturalismo" dirigidos contra la fenomenología, se vuelven justamente en contra suya, debido al culturalismo recalcitrante de su teoría. Si nada queda fuera de las normas en la teoría de la acción comunicativa, entonces su operatividad, su funcionamiento en la praxis de la interacción, hace retroceder el análisis de la interacción incluso hasta antes de Parsons; por tanto, tenemos una teoría eminentemente regresiva. Habermas le cierra el paso a las direcciones investigativas, como la praxeología del mundo cotidiano que caracteriza a la etnometodología, en sus más variadas versiones y tendencias, desde la etnometodología "clásica" plasmada en los Estudios en Etnometodología de 1967 hasta el Ehnomethodology' Program: working out Durkheim's aphorism, de 2002, obras centrales de Garfinkel.

Sólo un concepto de mundo de la vida encogido y limitado a lo normativo, cercenado a reglas de interacción y lenguaje que restringen la libertad existente de los participantes para generar reglas de comportamiento comunicativo flexibles, sustentadas en la intrínseca "vaguedad del lenguaje", ese mundo sí que es posible de colonizar, plausible de someterlo a acción estratégica (orientada al 
éxito) y de convertirlo en la quinta columna de un "sistema" de características dudosamente omnipotentes. Pero la práctica demuestra lo contrario y es irónicamente desde la teoría de sistemas de Luhmann, que se contradice radicalmente a la teoría de Habermas, postulando lo siguiente:

1. Los sistemas de interacción son auto-móviles, es decir, se mueven sin control externo.

2. Los sistemas de interacción son tan fugaces, tan efímeros, que es imposible diferenciarlos internamente.

3. Los sistemas de interacción saltan y juguetean de sistema en sistema, de tal manera que es imposible clasificarlos, controlarlos y dominarlos.

4. Los sistemas de interacción están dotados de una microdiversidad, que los convierte en independientes, incluso de la indexicalidad de sus propios contextos.

5. Sólo para los sistemas de interacción altamente institucionalizados (como los servicios religiosos, los exámenes orales o los juicios orales) existen reglas de comportamiento normativas. Pero estos eventos, son justamente por la etiqueta que los caracteriza, los más permeables y plausibles de desbaratar. Los conocidos experimentos de quiebre de Garfinkel (2006:47) así lo demuestran empíricamente.

6. Los sistemas de interacción están provistos, en aparente paradoja con las propiedades anteriores, de una autopoesis de propiedades indexicales, que les permiten obtener los recursos necesarios para su continuidad, desde su propio operar.

Un "buen" relato origina una buena conversación y se puede hablar de lo que se quiera, de Iron Maiden y su último concierto, de lo cambiante que se ha vuelto el clima, uno se puede reír de los chistes del profesor, por anticuados y obsoletos, o comentar la comida que en grupo se degusta. Ya no vivimos en la época de la "conversación de sociabilidad", donde cualquier crítica era extemporánea y mal vista. Los mundos de la vida se han vuelto tan polifacéticos y diversos, que es imposible clasificarlos de alguna manera.

Por último, es el propio Habermas quien reconoce el naufragio de su mundo de la vida, pues "el concepto de mundo de la vida desarrollado en términos de la teoría de la acción comunicativa todavía está lejos del grado de explicación de su oponente fenomenológico" (Habermas1987:204).

Se entiende el exagerado y acrítico apego de Habermas a lo normativo, pues esta ha sido una tendencia constante en sus obras anteriores. Esa debilidad tiene, como hemos visto, un costo muy alto en lo que respecta a su fallido intento de reformulación del mundo de la vida. Ciertamente, la calificación exagerada que tienen los valores, las normas, la integración y la diferenciación estructural tienen que ver claramente con la monumentalidad de la teoría de sistemas (y su concepción de los sistemas como acción). Sospechamos que esta es la razón por la cual su "crítica de la razón funcionalista" es débil y temerosa. Esto se pone de manifiesto en la asunción de la teoría de los medios sociales de intercambio de Parsons, cuestión que examinaremos a continuación.

3. Los medios sociales de interacción o de intercambio son parte de la obra tardía de Parsons de la década de 1980. Su interpelación fundamental es la estructura motivacional que subyace a las selecciones que alter y ego realizan en el curso de la interacción. Parsons es de la opinión que existen "aceleradores" motivacionales para la selección-acción, que fungen como medios sociales 
de interacción (entre alter y ego). Los medios de interacción son cuatro: el dinero, el poder, la influencia y los compromisos morales; a cada uno de ellos, les dedica un acucioso y detallando análisis. (a) El poder consiste en la capacidad de personas o colectivos para "conseguir algo", en contra de la resistencia o la oposición de otros y operando de manera de evitar (para ego) el menoscabo. (b) La influencia consiste en la posesión de determinados atributos (de alter) que inducen un efecto persuasivo en ego. Para Parsons, que argumenta muy finamente, el medio de la influencia es posible desubcodificar de varias maneras u ordenarlas por tipos: la influencia política, que se remite a la posesión de atributos que catalizan comportamiento referido al poder y la influencia fiduciaria, que impone el impulso de la selectividad apelando a la confianza y la influencia destinada a la apelación a distintos tipos de lealtad. (c) Los compromisos morales o commitments apelan a valores que subyacen en la estructura de ego y alter, por ejemplo, el mendigo que pide donaciones formula implícitamente la siguiente interpelación: "Te ofrezco mostrarte mi pobreza, entonces quiero que me des limosna". (d) El modelo que inspira a ésta teoría es el medio dinero, porque satisface tres funciones decisivas: el dinero es un medio de permuta, no un valor de uso; el dinero tiene una cualidad de homogeneización, porque permite comparar bienes y servicios, altamente heterogéneos y reducirlos; el dinero en un valor conservable y divisible, por lo que si se intercambia por mercancías, no es notable una desvalorización.

El dinero es el medio de intercambio que condiciona la aparición de la modernidad, según Parsons, porque introduce un medio de control sistémico en los procesos de intercambio económico. Ahora bien, la apática crítica de Habermas a la "razón funcionalista" finaliza de manera inaudita, nada menos que asumiendo la teoría de Parsons cambiándoles simplemente el nombre, él los llama "medios de control" y los agrupa en pares:

El primero de los grupos de los denominados medios de control, tienen la función de coordinar las acciones en las que Ego y Alter se orientan hacia el éxito, es decir, hacia la obtención de metas, su motivación es pragmático-empírica, y los medios tecnifican el mundo de la vida y sustituyen al lenguaje cotidiano como mecanismo privilegiado de opresión social. Estos medios deslingüistizados son obviamente el dinero y el poder. Ellos son los que garantizan la reproducción material, es decir, coadyuvan a la integración sistémica.

La influencia y los compromisos de valor son considerados como medios de comunicación, donde la orientación hacia el entendimiento de Ego y Alter presionan una motivación racional; es decir, abren la posibilidad de utilizar pretensiones de validez, problematizables en el marco de la orientación de Ego y Alter hacia una situación ideal de comunicación, y libre de toda presión de poder. Estos medios son los que garantizan la reproducción simbólica del mundo de la vida habermasiano. En la valiosa esquematización de Chernilo, este importante componente en la teoría de Habermas, "representa...un primer paso en la independización de la teoría de los medios frente al paradigma parsoniano" (Chernilo 1999), cuestión que no podemos en absoluto compartir.

Una somera constatación empírica de la postura habermasiana nos obliga a preguntarnos si el poder es realmente un medio que opera absolutamente divorciado del lenguaje, y si no termina, mediante el discurso político (independientemente de si sea válido, verdadero o demagógico) siendo completamente dependiente de la puesta en uso de elementos lingüísticos. Es muy cierto 
que los aspirantes a un cargo de representación lo que buscan simple y sencillamente es ganar a toda costa una elección, y que para ello no titubean en usar cualquier medio mantenido por el lenguaje, para persuadir a los electores. El sueño de todo aspirante a una cargo de representación es hacer uso de un lenguaje lo suficientemente convincente como para persuadir la conciencia del individuo-elector, para que en la soledad de la cámara de votación, marque su nombre en la lista de candidatos. Además, la comunicación de decisiones vinculantes, propiedad elemental de los sistemas políticos, no puede realizarse sin la puesta en uso de un lenguaje especializado que debe encontrar su propia mundanidad para arribar al entorno de la opinión pública compuesta por electores. Pero incluso en las interacciones más sutiles como las que se despliegan entre médicopaciente, también se pueden constatar estructuras indexicales de poder, como lo ha demostrado ten Have (1991:138-150). Luhmann, en su teoría del poder, nos recuerda que en el sentido más general, el poder es comunicación guiada por un código, y que obviamente en el marco del poder de las organizaciones, la sanción del poder organizacional, el despido, demuestra que el mecanismo de exclusión ocurre justamente por medio de la comunicación del lenguaje (Luhmann 1995:147). En síntesis, si todos los sistemas funcionales de la sociedad necesitan del lenguaje y de la comunicación para poder operar, la realización del poder lo requiere más que ningún otro, por lo tanto, no se trata de un medio deslingüistizado, como sostiene Habermas, sino de un medio que se acopla casi automáticamente a los sistemas de interacción más diversos del "mundo de la vida".

Aceptando que el medio dinero pueda operar escindido de la interacción, y aceptando (parcialmente) la postura de Giddens, para quien "el dinero es un medio de distanciamiento entre el espacio y el tiempo" (1999:35), el atributo fundamental de la modernidad. Digo, si el dinero en su forma desarrollada se define ante todo como posibilidad de crédito y deuda, la velocidad de las transacciones financieras requieren de un soporte comunicacional, de allí que el dinero genere su propio lenguaje comunicativo. Se trata de un lenguaje binario y reducido a la binariedad de su operar, que obviamente difiere sustancialmente del lenguaje policontextural de la cotidianeidad. Si el lenguaje binario (si/no) debe rechazar categóricamente el tertium non datur, es decir, un tercer valor destinado a complejizar (policontexturalizado) la comunicación, la praxis de la doxa cotidiana hace de su puesta en uso el fundamento de su operar, haciendo del lenguaje cotidiano el dispositivo de constitución de la comunicación, sustentada sobre la vaguedad y las imprecisiones que caracterizan el entendimiento y la compresión cotidianas. Pero no cualquiera puede acceder a los códigos de manipulación remota de una cuenta bancaria en las Islas Caimán. El individuo cotidiano compra en la feria y en el supermercado y para hacer funcionar los pagos por las mercancías que adquirió: debe poner en uso competencias comunicativas que son comunes a la sociedad a la cual pertenece. En otras palabras, tiene que "estar en el mundo de la vida", de lo contrario toda (o parte) de la normalidad se desmorona. Justamente, los experimentos de crisis de Garfinkel vienen a confirmar que nuestras actividades cotidianas, por muy obvias que parezcan, son tremendamente frágiles y porosas.

\section{Conclusiones y perspectivas abiertas latinoamericanas}

La modernidad es un producto europeo-occidental. Es un relato -para no usar el peyorativo término "meta-relato" que evoca al pensamiento postmoderno- de una genealogía y talante exclusivamente occidental. Es por ello que usamos el neologismo "eurocéntrico" o el apelativo "modernidad eurocéntrica" no como una representación de desprecio o de menoscabo a la ardua tarea de más de un siglo de elaboración teórica, de producción epistemológica y también de praxis 
investigativa realizado en las "fábricas" de reflexión europeas, sino para diferenciarlo de los esfuerzos surgidos hace más o menos una década en ciertos países de América Latina y que configuran el "proyecto latino/latinoamericano modernidad/colonialidad" (Castro Gómez y Gosfoguel 2007), mencionado en los inicios de este trabajo.

La elaboración de lo que podríamos llamar la modernidad decolonial latinoamericana está recién comenzando y es un proyecto de iniciación altamente prometedor, emprendido apenas por un puñado de pioneros, atrincherados en instituciones académicas, universidades y centros de investigación de la más variada procedencia científica e intelectual: historiadores, filósofos, antropólogos, semióticos, comunicadores sociales, escritores, poetas, etc. Por consiguiente, resultaría pretencioso y desmesurado desmerecer los esfuerzos de los clásicos de la modernidad eurocéntrica, como principalmente la obra de Simmel, Marx, Weber, Tarde y Durkheim, así como los productos más recientes, encarnados en figuras como Giddens, Habermas, Beck, Bauman, Lash, Latour, Foucault, Bourdieu y Luhmann, por mencionar los más importantes. El respeto que los occidentales se han ganado merecidamente, no debe ser confundido, empero, con un sometimiento acrítico o con un silencio de complicidad frente a sus errores e inconsistencias teóricas, como tampoco con sus insolencias y pretensiones de orden universalista, como lo hemos hecho en este trabajo. Esto principalmente porque el proyecto latinoamericano de modernidad no es compartido aún por una mayoría significativa de intelectuales de la región; esto es perfectamente comprensible, porque el nacimiento de la sociología, con Aguste Comte, fue aproximadamente coherente con la emergencia de las primeras manifestaciones empíricas de la modernidad europea.

El proyecto latinoamericano de modernidad, como todo proyecto emergente y todavía no suficientemente asentado, tiene fortalezas, pero también algunas debilidades. Permítaseme esbozar algunas de ellas, sin la menor intensión de abarcar toda la diversidad de autores que estos comentarios merecerían. Comenzaré con las fortalezas.

En primer lugar, una de las fortalezas de éste paradigma emergente se refieren a la redefinición realizada por los latinoamericanos del carácter y el papel de la colonialidad y a la emergencia real de la modernidad occidental. La "modernidad" nace en realidad con el descubrimiento del Nuevo Mundo en 1492 y no es el resultado de procesos históricos intraeuropeos, salvo que nos remitamos al llamado "estado natural" de la humanidad, que es una fábula desmesurada creada por Hobbes y Rousseau o a Kant con su hipóstasis racionalista. La evidencia histórico-empírica es hoy en día indiscutible y reconocida por todos los expertos (Dussel 2000:59 ss.). El proyecto descolonizador latinoamericano, al exponer a la superficie del discurso histórico-social la cara oculta de la modernidad-la colonialidad del poder, el exterminio y la explotación de los pueblos originarios, la destrucción y el ultraje de la Otredad, oculta en la Mismidad- resignifica el valor y la historia de "nuestra América" (Martí) y pone en tela de juicio la pretenciosa historia eurocéntrica de la modernidad, escrita por los vencedores, descendientes intelectuales y políticos de los conquistadores. $Y$ lo hace sin sucumbir a las tentaciones postmodernas, como señala en proyecto alternativo de transmodernidad elaborado por Dussel (2000:62).

En segundo lugar, otra de las fortalezas de éste paradigma fundacional se remite a la translocalización de la idea de América Latina en el contexto de la globalización. Y con ello me refiero a una serie de obras de compilación aparecidas en los últimos años (Castro-Gómez y 
Mendieta 1998, Castro-Gómez 2000, Lander 2000, Castro-Gómez y Gosfoguel 2007). Esta translocalización va seguida de una profunda crítica postcolonial a la razón (Castro-Gómez y Mendieta 1998:169) y de una discusión delimitadora del proyecto postcolonial latinoamericano con el pensamiento postmoderno (Mendieta 1998:147). Esta resignificación del traslado de las rutas comerciales mercantiles desde el Mediterráneo hacia el Atlántico, va acompañada de una diferenciación profunda entre la modernidad sajona (referida a los EEUU) y la modernidad latinoamericana. Quijano (2000:201) se encarga de distinguir tres modelos históricamente diferenciados de colonización extranjera de América, fundamento de la colonialidad del poder: (i) el modelo norteamericano y sus propiedades específicas, en especial el exterminio casi total de etnias originarias, proceso que precede a una inmensa ola migratoria en EEUU proveniente de Europa; (ii) el modelo del Cono Sur de América Latina (Argentina, Uruguay y Chile), aparentemente muy similar al anterior; (iii) la potencialidad del resto de América Latina, donde una mayoría indígena es sometida por una minoría blanca.

En tercer lugar, entre sus fortalezas, debiéramos agregar el distanciamiento de sus principales exponentes de la teoría marxista de la sociedad (Quijano 2007:93), a pesar de que la mayor parte de sus exponentes se sienten herederos de las tradiciones esparcidas por la teoría de la dependencia, y el rescate de autores indigenistas que ocuparon hasta hace poco un lugar marginal en el pensamiento latinoamericano, como es el caso de José Carlos Mariátegui, Martí y otros tantos. Si el marxismo es entendido como una forma particular de eurocentrismo, en lo esencial la contradicción fundamental de América Latina no se formula en términos de capital (dominante)/trabajo (asalariado), sino entre etnia/trabajo.

En cuarto lugar, uno de los méritos más importantes de este paradigma consiste en haber resituado históricamente la importancia de América Latina en el contexto de la colonialidad y destacado su rol fundamental en la reestructuración de las rutas comerciales mundiales, destacando la "colonización cognitiva" que significó la dominación colonial, como la "doble conciencia criolla" que caracterizó los procesos independentistas de 1808 en adelante, hasta hoy presente en la polisemia de las realidades de la región. Mientras que la "colonización cognitiva" nos impulsa a observar distorcionadamente la especificidad de nuestras realidades (como por ejemplo la subsunción de todos los problemas estructurales a la distinción tradicional/moderno, y a ver en el desarrollo la panacea para su solución), la "doble conciencia criolla" generada por los proyectos independentistas de principios del siglo XIX (en su mayoría frustrados), e influenciados por la llustración europeizante, encuentra su proyección en el imaginario de la Otredad indígena, evaluada como minusválida y atrasada por las distintas elites (blancas o mestizas) en el poder. Justamente la adopción de la americanidad significa, para Mignolo, "vivir en medio de los borramientos de la colonialidad" (2007:77). La matriz colonial del poder, invisible a causa del triunfo de la retórica de la modernidad y la modernización, consiste en la capacidad del sistema de dominación para reducir las diferencias y considerarlas como inexistentes y realizar una categorización racial que convierte a las vidas humanas en entes prescindibles.

Por consiguiente, la otra cara de la modernidad no es la individualización, como argumentan los "ego-políticos" de la retórica de la modernidad, Ulrich Beck, Giddens y Habermas, sino que para nosotros, la cara oculta de la modernidad, es y seguirá siendo la colonialidad. La distinción de (y entre) modernidad/individualización y modernidad/colonialidad es el punto de quiebre entre las 
visiones imperiales de la modernidad (acompañadas de la crítica postmoderna a la modernidad, realizada desde la matriz imperial) y el proyecto decolonizador latinoamericano.

En quinto lugar, otra de las grandes virtudes de este paradigma es haber comenzado a relacionar creativamente el análisis histórico de orden macro-sociológico con las estructuras de aculturación y socialización, vigentes en países como Venezuela y la región del Caribe, utilizado creativamente el complejo aparataje de la fenomenología (Moreno 1995), y haber emprendido la búsqueda concreta de la Alteridad, en la forma de una nueva episteme relacional. Sin la mayor exageración, Moreno señala que desde el pueblo caribeño, se está gestando una nueva episteme relacional en los mundos de vida y en las familias.

En sexto lugar, no puede dejar de destacarse la revitalización y el fortalecimiento del rol del fenómeno del colonialismo interno, desarrollado por González Casanova (1978:220), y resituado en la perspectiva de la colonialidad del poder en América Latina.

Por supuesto que la sumatoria anterior no tiene ninguna pretensión de completitud y menos aún abarca todos los tópicos que el paradigma innovadoramente contiene. Pero tal como destaqué en tono de admiración las fortalezas de éste paradigma, voy a enumerar las que a mi juicio son sus principales debilidades. Partiré apuntando que éste paradigma innovador es muy fuerte en lo histórico, pero es débil en lo sociológico. Puede ser que la afirmación anterior parezca injusta y atrevida, pero se explica (al menos en parte) por la heterogeneidad y el origen académico de los sostenedores del mismo.

(a) Constato un uso descuidado del concepto de intersubjetividad. Creo que la hipótesis de la colonización de la intersubjetividad, sostenida por Quijano y otros, deja sin esclarecer si se trata de la intersubjetividad normativa de Habermas, o a las que defiende el paradigma fenomenológico, 0 simplemente se da por descontado que el mundo social se construye intersubjetivamente, lo cual es sumamente discutible. Sea como fuere, y sobre todo si el concepto permanece impensado, habría que recordar que hay quienes consideran la existencia de la intersubjetividad como elemento constitutivo del mundo como una vulgar patraña (Castoriadis 1997) y quienes resaltan su dudosa utilidad para el análisis sociológico (Luhmann 1998:31).

(b) De la misma manera, cuestiono el uso incuestionado del concepto de imaginario social, concepto del cual se sirven la mayoría de sus autores. Sería obligatorio referirse a la obra de Cornelius Castoriadis y no refugiarse en autores menores como Glissant. El concepto de imaginario social, diferente del de "representación social" ha sido suficientemente desarrollado y representa, hoy en día, uno de los paradigmas emergentes de mayor connotación.

(c) Cuando Mignolo (2000), por citar solamente un ejemplo, se refiere al fenómeno de la doble conciencia criolla es notable el uso exclusivamente historicista que al término le asigna, cuando en realidad la "doble conciencia criolla" es la expresión de estructuras comunicacionales inauguradas con los movimientos de independencia y que se mantienen transmutadas hasta la actualidad. Es notable el prejuicio absolutamente injustificado que el paradigma del que nos ocupamos tiene con respecto a la teoría de sistemas, es especial a la teoría de la sociedad de Niklas Luhmann. 
(d) Constato un excesivo acercamiento a la "teoría crítica" de la sociedad. Así por ejemplo, Mignolo pregunta "¿en qué podría ayudarnos una teoría crítica que surgiría de la historia interna de Europa misma desde la perspectiva de los colonizados internos (los judíos) en la historia de Europa desde 1492? ¿Qué debería a aspirar a ser la teoría crítica cuando los condenados de la tierra están en la escena junto al proletariado de Max Horkheimer o junto a la actual traducción del proletariado como multitud?" (Mignolo 2010:8). En mi opinión, la respuesta es muy simple: por supuesto que la teoría crítica en nada puede ser un apoyo a los estudios latinoamericanos, porque no se ha interesado ni le interesan esos asuntos "exóticos" y lejanos de Europa. Este acercamiento de búsqueda infructuosa en la teoría crítica es principalmente notable en los trabajos de Castro-Gómez. Si examinamos, por ejemplo, un libro paradigmático y político de Habermas, como La Inclusión del Otro, su preocupación e interés de conocimiento se centra exclusivamente en problemas europeos, en particular en la necesidad de una "constitución europea" (Habermas 1999:137) y otras yerbas, que por supuesto nada tienen que ver con asuntos latinoamericanos. Por lo tanto, este empeño de aproximación resulta ser obviamente una soberana pérdida de tiempo (y de papel).

(e) Una clara muestra de falta de información teórica es la Introducción de Castro-Gómez y Gosfoguel, al compilado El Giro Decolonial. En dicha introducción, los autores destacan la importancia del "pensamiento heterárquico", y agregan que las heterarquías "son estructuras complejas en las que no existe un nivel básico que gobierna sobre las demás, sino que todos los niveles ejercen algún grado de influencia mutua en diferentes aspectos particulares" (CastroGómez y Gosfoguel 2007:18). Pero el concepto de heterarquía fue descubierto y usado por primera vez por el neurofisiólogo y teórico de la cibernética Warren McCulloch en 1945 y hoy día pertenece al lenguaje de la teoría de sistemas.

Con las apreciaciones críticas expuestas quiero llamar la atención acerca de las debilidades que presenta el proyecto de descolonización presente en América Latina, con las mejores intenciones. Justamente porque a lo largo de este trabajo he procurado demostrar tanto las debilidades de la modernidad eurocéntrico-universalista como su dudosa utilidad para un proyecto latinoamericano, decolonial y particularista.

\section{Bibliografía}

Benjamin, W. 1991. Gesammelte Schriften. Frankfurt: Suhrkamp.

Beriain, J. 2005. Modernidades en disputa. Barcelona: Anthropos.

Castoriadis, C. 1997. Poder, política, autonomía. Buenos Aires: Altamira

Castro-Gómez, S. 2000. La reestructuración de las ciencias sociales en América Latina. Bogotá: Pensar/Universidad Javieriana.

Castro-Gómez, S. y Mendieta, E. 1998. Teorías sin disciplina. Latinoamericanismo, postcolonialidad y globalización en debate. México: Porrúa.

Castro-Gómez, S. y Gosfoguel, R. 2007. El giro decolonial. Reflexiones para una diversidad epistémico más allá del capitalismo global. Bogotá: Siglo del Hombre.

Chernilo, D. 1999. Integración y diferenciación. Cinta moebio 6: 1-30. 
Descartes, R. 1974. Meditaciones metafísicas. Santiago: Editorial Universitaria.

Dussel. E. 2000. Europa, modernidad y eurocentrismo. En: E. Lander. La colonialidad del saber. Caracas: Faces/UNESCO, pp. 59-78.

Elias, N. 1996. La sociedad cortesana. México: FCE.

Garfinkel, H. 2006. Estudios en etnometodología. Barcelona: Anthropos.

Giddens, A. 1999. Consecuencias de la modernidad. Madrid: Alianza.

González Casanova, P. 1978. Sociología de la explotación. México: Siglo XXI.

Habermas, J. 1981. Theorie del kommunikativen Handelns (Tomo I). Frankfurt: Suhrkamp.

Habermas, J. 1985. El discurso filosófico de la modernidad. Madrid: Taurus.

Habermas, J. 1987. Teoría de la acción comunicativa Tomo II. Madrid: Taurus.

Habermas, J. 1998. Die postnationale Konstellation. Politische essays. Frankfurt: Suhrkamp.

Habermas, J. 1999. La inclusión del otro. Estudios de teoría política. Barcelona: Paidós.

Hegel, G.W. 1980. Lecciones sobre historia de la filosofía I. Madrid: Altaya.

Husserl, E. 1993. Ideas relativas a una fenomenología pura y una filosofía fenomenológica. México: FCE.

Kant, I. 1965. Filosofía política. Buenos Aires: Nova.

Lander, E. 2000. La colonialidad del saber: eurocentrismo y ciencias sociales. Perspectivas latinoamericanas. Caracas: Faces/UNESCO.

Latour, B. 2007. Nunca fuimos modernos. Buenos Aires: Siglo XXI.

Levi-Strauss, C. 1972. El pensamiento salvaje. México: FCE.

Luhmann, N. 1985. El amor como pasión. La codificación de la intimidad. Madrid: Península.

Luhmann, N. 1995. Poder. Barcelona: Anthropos.

Luhmann, N. 1997. Observaciones de la modernidad. Barcelona: Paidós.

Luhmann, N. 1998. Gesellschaftstruktur und Semantik Tomo I. Frankfurt: Suhrkamp.

Marx, C. 1975. El capital. Crítica de la economía política. México: FCE.

Mendieta, E. 1998. Modernidad, postmodernidad y postcolonialidad: una búsqueda esperanzadora del tiempo. En: S. Castro-Gómez y E. Mendieta. Teorías sin disciplina. México: Porrúa, pp. 147-168.

Mignolo, W. 2000. La colonialidad a lo largo y a lo ancho. El hemisferio occidental en el horizonte colonial de la modernidad. En: E. Lander. La colonialidad del saber. Caracas: Faces/UNESCO, pp. 79-117.

Mignolo, W. 2007. La idea de América Latina. La herida colonial y la opción decolonial. Barcelona: Gedisa.

Mignolo, W. 2010. Desobediencia epistémica: retórica de la modernidad, lógica de la colonialidad y gramática de la descolonialidad. Buenos Aires: Ediciones del Siglo. 
Moreno, A. 1995. El aro y la trama. Episteme, modernidad y pueblo. Caracas: Ediciones CIP.

Moreno, A. 2000. Superar la exclusión, conquistar la equidad: reformas, políticas y capacidades en el ámbito social. En: E. Lander. La colonialidad del saber. Caracas: Faces/UNESCO, pp. 227-246.

Quijano, A. 2000. Colonialidad del poder, eurocentrismo y América Latina. En: E. Lander. La colonialidad del saber. Caracas: Faces/UNESCO, pp. 281-348.

Quijano, A. 2007. Colonialidad del poder y clasificación social. En: S. Castro-Gómez y R. Gosfoguel. El giro decolonial. Bogotá: Siglo del Hombre, pp. 93-125.

Schütz, A. 1971. Das Problem der Relevaz. Frankfurt: Suhrkamp.

Schütz, A. 1993. La construcción significativa del mundo social. Buenos Aires: Paidós.

Schütz, A. 1995. El problema de la realidad social. Buenos Aires: Amorrortu.

Schütz, A. y Luckmann, T. 2003. Las estructuras del mundo de la vida. Buenos Aires: Amorrortu.

Schütz, A. y Parsons, T. 1977. Zur Theorie des sozialen Handelns. Ein Briefwechsel. Frankfurt: Suhukamp.

Simmel, G. 1988. Sobre la aventura. Ensayos filosóficos. Barcelona: Península.

Sombart, W. 1979. Lujo y capitalismo. Madrid: Alianza.

Sombart, W. 1993. El Burgués. Contribución a la historia espiritual del hombre económico moderno. Madrid: Alianza.

ten Have, P. 1991. A reconsideration of the "asymmetry" of doctor-patient interaction. En: D. Boden y D. Zimmernan. Talk and social structure. Studies in ethnomethodology and conversation analysis. Berkeley: University of California Press, pp. 138-150.

Weber, M. 1969. La ética protestante y el espíritu del capitalismo. Barcelona: Península.

Weber, M. 1993. Ensayos sobre metodología sociológica. Buenos Aires: Amorrortu.

Weber, M. 1997. Sociología de la religión. Madrid: Istmo.

Recibido el 27 Jun 2012

Aceptado el 15 Sep 2012 